\title{
Variations of oxygen-18 in West Siberian precipitation during the last 50 years
}

\author{
M. Butzin ${ }^{1,2}$, M. Werner ${ }^{1}$, V. Masson-Delmotte ${ }^{3}$, C. Risi ${ }^{4}$, C. Frankenberg ${ }^{5}$, K. Gribanov ${ }^{2}$, J. Jouzel ${ }^{3}$, and \\ V. I. Zakharov ${ }^{2}$ \\ ${ }^{1}$ Alfred Wegener Institute, Helmholtz Centre for Polar and Marine Research, Bremerhaven, Germany \\ ${ }^{2}$ Climate and Environmental Physics Laboratory, Ural Federal University, Yekaterinburg, Russia \\ ${ }^{3}$ Laboratoire des Sciences du Climat et de l'Environnement, IPSL (CEA, CNRS, UVSQ), Orme des Merisiers, \\ Gif-sur-Yvette, France \\ ${ }^{4}$ Laboratoire de Météorologie Dynamique, IPSL, UPMC, CNRS, Paris, France \\ ${ }^{5}$ Jet Propulsion Laboratory, California Institute of Technology, Pasadena, USA
}

Correspondence to: M. Butzin (martin.butzin@awi.de)

Received: 1 October 2013 - Published in Atmos. Chem. Phys. Discuss.: 8 November 2013

Revised: 7 April 2014 - Accepted: 27 April 2014 - Published: 13 June 2014

\begin{abstract}
Global warming is associated with large increases in surface air temperature in Siberia. Here, we apply the isotope-enabled atmospheric general circulation model ECHAM5-wiso to explore the potential of water isotope measurements at a recently opened monitoring station in Kourovka $\left(57.04^{\circ} \mathrm{N}, 59.55^{\circ} \mathrm{E}\right)$ in order to successfully trace climate change in western Siberia. Our model is constrained to atmospheric reanalysis fields for the period 1957-2013 to facilitate the comparison with observations of $\delta \mathrm{D}$ in total column water vapour from the GOSAT satellite, and with precipitation $\delta^{18} \mathrm{O}$ measurements from 15 Russian stations of the Global Network of Isotopes in Precipitation. The model captures the observed Russian climate within reasonable error margins, and displays the observed isotopic gradients associated with increasing continentality and decreasing meridional temperatures. The model also reproduces the observed seasonal cycle of $\delta^{18} \mathrm{O}$, which parallels the seasonal cycle of temperature and ranges from $-25 \%$ in winter to $-5 \%$ in summer. Investigating West Siberian climate and precipitation $\delta^{18} \mathrm{O}$ variability during the last 50 years, we find long-term increasing trends in temperature and $\delta^{18} \mathrm{O}$, while precipitation trends are uncertain. During the last 50 years, winter temperatures have increased by $1.7^{\circ} \mathrm{C}$. The simulated long-term increase of precipitation $\delta^{18} \mathrm{O}$ is at the detection limit ( $<1 \%$ o per 50 years) but significant. West Siberian climate is characterized by strong interannual variability, which in winter is strongly related to the North Atlantic Oscil-
\end{abstract}

lation. In winter, regional temperature is the predominant factor controlling $\delta^{18} \mathrm{O}$ variations on interannual to decadal timescales with a slope of about $0.5 \%{ }^{\circ} \mathrm{C}^{-1}$. In summer, the interannual variability of $\delta^{18} \mathrm{O}$ can be attributed to shortterm, regional-scale processes such as evaporation and convective precipitation. This finding suggests that precipitation $\delta^{18} \mathrm{O}$ has the potential to reveal hydrometeorological regime shifts in western Siberia which are otherwise difficult to identify. Focusing on Kourovka, the simulated evolution of temperature, $\delta^{18} \mathrm{O}$ and, to a smaller extent, precipitation during the last 50 years is synchronous with model results averaged over all of western Siberia, suggesting that this site will be representative to monitor future isotopic changes in the entire region.

\section{Introduction}

For the last several decades, an unequivocal warming of the climate system has been reported, evident from observations of increasing global average air and ocean temperatures, widespread melting of snow and ice and rising globalmean sea level (IPCC, 2013). However, while the rate of global warming averaged over the last 50 years amounts to about $0.1{ }^{\circ} \mathrm{C}$ per decade, high-latitude regions of the Northern Hemisphere, such as Siberia, have been warming at considerably higher rates (e.g. Tingley and Huybers, 2013, and 
references therein). Positive feedbacks associated with snow and sea-ice albedo, water vapour, clouds, and moisture transport as well as complex land surface-atmosphere interactions have been discussed as possible reasons for the observed Arctic amplification (for an overview see Masson-Delmotte et al. (2013), and references therein). While most studies so far have been focussed on the observed present and projected future temperature increase, it is uncertain how much other components of the Arctic climate system (like the hydrological cycle) will change as a consequence of the temperature rise. Bengtsson et al. (2011) estimated that the strength of the Arctic water cycle, in terms of annual precipitation, may increase by some $25 \%$ by the end of the 21 st century.

Since the pioneering work of Dansgaard (1953, 1964), Craig (1961), Merlivat et al. (1973), Sonntag et al. (1976), and others, it is well known that changes in climate and the atmospheric water cycle leave an imprint on the isotopic composition of different water reservoirs on earth. For meteoric water, Dansgaard (1964) successfully explained (through the atmospheric distillation process) the linear relation between the isotopic composition of precipitation and the local temperature at the precipitation site (the so-called "temperature effect") observed in many mid- to high latitude regions on earth. Assuming that the observed spatial and temporal isotope-temperature relationships are equivalent and constant in time (see Jouzel et al., 2000, for a review of this assumption), it is possible to infer past temperatures from stable water isotopes. Given the magnitude of Arctic warming over the past decades, climate change should be recorded in the isotopic composition of meteoric waters (or natural archives) in boreal regions of the Northern Hemisphere. The magnitude of this isotopic response is of interest when it comes to reconstructing past regional climate changes via isotopic data retrieved from various palaeoclimate archives (e.g. Sidorova et al., 2010).

Unfortunately, isotope records of present-day boreal precipitation are sparse and discontinuous. For Russia, Kurita et al. (2004) have reviewed the modern isotope climatology. Data from 13 Russian monitoring sites sampled during the period 1996-2000 depict eastward isotopic depletion over Russia, which is explained by the gradual rain-out of moist, oceanic air masses, which are transported towards and over Russia by westerly winds. This isotopic gradient, established from earlier isotope records, is known as the "continental effect" (e.g. Araguas-Araguas et al. (2000), and further references therein). The continental effect weakens in summer due to continental moisture recycling. Altogether, Kurita et al. (2004) estimate that $55 \%$ of the summertime isotopic variability in Russian precipitation is linked to temperature changes and variations of the recycling ratio of continental water sources, the latter effect accounts for just $20 \%$ of the signal. Combining simulation results of the isotope-enabled atmospheric general circulation model (AGCM) LMDZiso with satellite-based estimates of the isotopic composition of water vapour, Risi et al. (2013) found that intraseasonal vari- ations in continental recycling are minor contributions to the isotopic variability of high-latitude summer precipitation.

To study the impact of climate change in western Siberia, the Russian "mega-grant" research project "Impact of climate change on water and carbon cycles of western Siberia" (WSibIso, http://wsibiso.ru) has recently started monitoring the isotopic composition of water vapour and precipitation at two high-latitude sites in western Siberia. At Kourovka Observatory $\left(57.04^{\circ} \mathrm{N}, 59.55^{\circ} \mathrm{E}\right)$, located approximately $80 \mathrm{~km}$ west of Yekaterinburg, isotope monitoring started in 2012 (Gribanov et al., 2014), while regular isotope measurements at Labytnangi $\left(66.65^{\circ} \mathrm{N}, 66.40^{\circ} \mathrm{E}\right)$ began in summer 2013.

Within the WSibIso Project, the understanding of the signals recorded at Kourovka and Labytnangi is supported by state-of-the-art climate simulations with two AGCMs equipped with explicit stable water isotope diagnostics, ECHAM5-wiso (Werner et al., 2011) and LMDZiso (Risi et al., 2010a). Such isotope-enabled AGCMs provide a mechanistic understanding of the atmospheric processes influencing the isotopic composition of meteoric water. Since the pioneering work of Joussaume et al. (1984), Jouzel et al. (1987), Hoffmann et al. (1998) and others, about a dozen stateof-the-art GCMs have been equipped with explicit isotope diagnostics (see Sturm et al., 2010, for a detailed model overview). A number of studies have clearly demonstrated their usefulness for an improved climatic interpretation of present and past water isotope variability (e.g. Jouzel et al., 2000; Mathieu et al., 2002; Noone and Simmonds, 2002; Werner and Heimann, 2002; Vuille and Werner, 2005; Lee and Fung, 2008; Tindall et al., 2009; Risi et al., 2010b). A comparison of different models allows for the evaluation of robust features, and the ability to scrutinize each model's parametrizations.

For Kourovka Observatory, the observed variations of the surface vapour isotopic composition are very similar to the results of the ECHAM5-wiso simulation covering the period April to September 2012 (Gribanov et al., 2014). Both exhibit short-term fluctuations on timescales from a few hours to a few days. These variations can be attributed to the passage of synoptic-scale weather systems, advecting air from different source regions with different isotopic signatures to Kourovka (Gribanov et al., 2014). A detailed comparison of the Kourovka data with LMDZiso model results will be presented in an accompanying paper (Gryazin et al., 2014).

Here, we extend the isotope analyses from year 2012 to the last 50 years. As there are no Russian water vapour isotope measurements available prior to 2012, the extended time frame implies that we focus on the isotopic composition of precipitation. Our key questions are as follows. (1) How much has the isotopic composition of precipitation varied in western Siberia over the last five decades? (2) What are the main mechanisms and processes causing the variations? (3) How well can large-scale West Siberian climate and water cycle variations be observed in the isotopic composition of precipitation at Kourovka Observatory, one of the 
key monitoring sites within the WSibIso project? Our analysis is based on a so-called "nudged" ECHAM5-wiso climate simulation performed for the period 1957-2013, covering the entire period of available ECMWF reanalysis data (Uppala et al., 2005; Berrisford et al., 2011; Dee et al., 2011).

The paper is arranged as follows: after a description of the model setup we test the model performance with respect to various observational data sets. In particular, we present a thorough comparison of simulated and observed precipitation $\delta^{18} \mathrm{O}$ in Russia, going beyond the previous global model assessment by Werner et al. (2011). This validation is a prerequisite for the following discussion of isotopic interannual variability and mechanisms during the last decades and of the representativeness of Kourovka in this context. We finish with conclusions regarding the potential of isotope measurements at Kourovka to trace future climate changes in western Siberia.

\section{Methods}

\subsection{Model description}

Atmospheric simulations were carried out using ECHAM5wiso (Werner et al., 2011), which is the isotope-enabled version of the atmospheric general circulation model ECHAM5 (Roeckner et al., 2003; Hagemann et al., 2006; Roeckner et al., 2006). The model considers both stable water isotopes $\mathrm{H}_{2}^{18} \mathrm{O}$ and $\mathrm{HDO}$, which have been explicitly implemented into its hydrological cycle, analogous to the isotope modelling approach used in the previous model versions ECHAM3 (Hoffmann et al., 1998) and ECHAM4 (e.g. Werner et al., 2001). For each phase of "normal" water (vapour, cloud liquid, cloud ice) being transported independently in ECHAM5, a corresponding isotopic counterpart is implemented in the model code. Isotopes and "normal" water are described identically in the AGCM as long as no phase transitions take place. Therefore, the transport scheme for all water-related variables is the flux-form semi-Lagrangian transport scheme for positive definite variables implemented in ECHAM5 (Lin and Rood, 1996).

Additional fractionation processes are defined for the water isotope variables whenever a phase change of the "normal" water occurs in ECHAM5 (considering equilibrium and non-equilibrium fractionation processes). Equilibrium fractionation takes place if the corresponding phase change is slow enough to allow full isotopic equilibrium (Merlivat and Jouzel, 1979). On the other hand, non-equilibrium processes even depend on the velocity of the phase change, and therefore on the molecular diffusivity of the water isotopes (Jouzel and Merlivat, 1984). Processes involving isotopic fractionation include the evaporation from the ocean, condensation either to liquid or to ice, as well as re-evaporation of liquid precipitation within the atmosphere. For evapotranspiration from land surfaces, possible isotopic fractionation is ne- glected (see Hoffmann et al. (1998) and Haese et al. (2013), for a detailed discussion of this issue).

ECHAM5-wiso has been evaluated against observations of isotope concentrations in precipitation and water vapour, both on a global and on a European scale (Langebroek et al., 2011; Werner et al., 2011). On both scales, annual and seasonal ECHAM-5-wiso simulation results are in good agreement with available observations from the Global Network of Isotopes in Precipitation, GNIP (IAEA/WMO, 2013).

Werner et al. (2011) have shown that the simulation of water isotopes in precipitation clearly improves with increased horizontal and vertical model resolution. Thus, for this study, we choose a horizontal model resolution of T63 in spectral space (horizontal grid size of approximately $1.9^{\circ} \times 1.9^{\circ}$ ), and a vertical resolution of 31 levels on hybrid sigmapressure coordinates. Local ECHAM5-wiso results for GNIP stations (discussed further below) were obtained by bilinear interpolation to the station coordinates. To ensure a most realistic simulation of present-day climate variability, the model is forced with prescribed yearly values of present-day insolation and greenhouse gas concentrations (IPCC, 2000), as well as with monthly varying fields of sea-surface temperatures and sea-ice concentrations according to ERA-40 and ERA-Interim reanalysis data (Uppala et al., 2005; Berrisford et al., 2011; Dee et al., 2011). Furthermore, the dynamicthermodynamic state of the ECHAM model is constrained to reanalysis data by an implicit nudging technique $(\mathrm{Kr}-$ ishamurti et al., 1991; the implementation in ECHAM is described by Rast et al., 2013) - i.e. modelled fields of surface pressure, temperature, divergence and vorticity are relaxed to the corresponding ERA-40 and ERA-Interim reanalysis fields (Uppala et al., 2005; Berrisford et al., 2011; Dee et al., 2011). The nudging interval is 6 hours, ensuring that the simulated large-scale atmospheric flow is modelled in agreement with the ECMWF reanalysis data on all analysed timescales. In contrast to the atmospheric flow, the hydrological cycle and its isotopic variations is still fully prognostic and not nudged to any reanalysis data. Vegetation in the model is prescribed by a time-invariant set of land surface data (vegetation ratio, leaf area index, forest ratio, background albedo; Hagemann, 2002).

The performed simulation covers the period September 1957 until July 2013. Here we regard the first 28 months as model spin-up and analyse the 51-year period between 1960 and 2010. Unless stated otherwise, we focus on monthly averaged model results of the isotopic composition of precipitation (typically expressed in a delta-notation as $\delta^{18} \mathrm{O}$ or $\delta \mathrm{D}$ ), covering the full period of available stable water isotope measurements in Russia.

\subsection{Observations of isotopes in Russian precipitation}

In western Siberia (here defined as the region ranging from $55-90^{\circ} \mathrm{E}$ and $55-70^{\circ} \mathrm{N}$ ), monthly precipitation $\delta^{18} \mathrm{O}$ data are available from 9 GNIP stations operating for different time 
Table 1. GNIP $\delta^{18} \mathrm{O}$ records from Russia considered in this study. Stations located in western Siberia are highlighted in bold. For each station, we report the latitude, longitude and altitude, as well as the sampling period $\left(t_{\mathrm{obs}}\right)$ and the number of available monthly measurements $\left(N_{\mathrm{obs}}\right)$.

\begin{tabular}{lccccc}
\hline Name & Lat $\left({ }^{\circ} \mathrm{N}\right)$ & Lon $\left({ }^{\circ} \mathrm{E}\right)$ & Alt $(\mathrm{m})$ & $t_{\text {obs }} \delta^{18} \mathrm{O}$ & $N_{\text {obs }} \delta^{18} \mathrm{O}$ \\
\hline Arkhangelsk & 64.58 & 40.50 & 13 & $1981-1990$ & 78 \\
Astrakhan & 46.25 & 48.03 & -18 & $1980-2000$ & 168 \\
Bagdarin & 54.47 & 113.58 & 903 & $1996-2000$ & 34 \\
Barabinsk & $\mathbf{5 5 . 3 3}$ & $\mathbf{7 8 . 3 7}$ & $\mathbf{1 2 0}$ & $\mathbf{1 9 9 6 - 2 0 0 0}$ & $\mathbf{3 7}$ \\
Cherskiy & 68.76 & 161.34 & 30 & $2001-2009$ & 57 \\
Kalinin & 56.90 & 35.90 & 31 & $1980-1988$ & 94 \\
Kirov & 58.65 & 49.62 & 164 & $1980-2000$ & 102 \\
Moscow & 55.75 & 37.57 & 157 & $1970-1979$ & 61 \\
Murmansk & 68.97 & 33.05 & 46 & $1980-1990$ & 71 \\
Pechora & $\mathbf{6 1 . 1 2}$ & $\mathbf{5 7 . 1 0}$ & $\mathbf{5 6}$ & $\mathbf{1 9 8 0 - 1 9 9 0}$ & $\mathbf{7 9}$ \\
Perm & $\mathbf{5 7 . 9 5}$ & $\mathbf{5 6 . 2 0}$ & $\mathbf{1 6 1}$ & $\mathbf{1 9 8 0 - 1 9 9 0}$ & $\mathbf{7 9}$ \\
Rostov & 47.25 & 39.82 & 77 & $1980-1990$ & 74 \\
Saratov & 51.57 & 46.03 & 166 & $1980-1990$ & 74 \\
St. Petersburg & 59.97 & 30.30 & 4 & $1980-1990$ & 107 \\
Yakutsk & 62.08 & 129.75 & 107 & $1978-2000$ & 46 \\
\hline
\end{tabular}

periods between 1973 and 2000. Individual records range from a few months to up to 10 years. Given the sparseness of these observations, we also include data from 12 other GNIP stations in Russia for an improved model evaluation. Except for Cherskiy $\left(68.76^{\circ} \mathrm{N}, 161.34^{\circ} \mathrm{E}\right)$, there are no published stable water isotope data for more recent times than the year 2000 (S. Terzer, personal communication, 2014).

To this set of 21 GNIP stations, we apply the following data selection:

(a) We consider only stations where the sampling period of isotopes in precipitation has been at least 5 years.

(b) Unrealistic delta values of approximately $+50 \%$ for both $\mathrm{HDO}$ and $\mathrm{H}_{2}^{18} \mathrm{O}$ isotopes from Amderma are excluded.

(c) Five outliers with anomalous positive delta values from Barabinsk and Yakutsk stations are excluded.

(d) We exclude six stations (Kandalaksa, KhantyMansiysk, Kursk, Olenek, Salekhard, and Terney) where reported monthly mean temperatures are clearly unrealistic (i.e. reporting winter values for summer months or vice versa) and systematically disagree from WMO measurements and/or ECMWF reanalysis data, indicating issues with data quality control within the GNIP database.

After data filtering, our database consists of results from 15 GNIP stations (comprising 1161 monthly observations of $\delta^{18} \mathrm{O}$ between 1970 and 2009; Table 1) used hereafter for further analyses.

\subsection{Satellite observations of isotopes in water vapour}

Although precipitation and water vapour have a different isotopic composition due to fractionation processes, a comparison of ECHAM5-wiso results for isotopes in water vapour with available data from satellite and ground-based remote sensing techniques is valuable. It will reveal some first-order information if the model correctly simulates the spatial gradients of the isotopic signal in atmospheric water vapour (and thus consistently in precipitation) over Russia. Ground-based remote sensing of $\delta^{18} \mathrm{O}$ in water vapour has been realized recently (Rokotyan et. al., 2014) but so far, only a small number of measurements have been carried out. For this reason we consider global observations of deuterium $(\delta \mathrm{D})$ in total column water vapour retrieved from the GOSAT satellite (Boesch et al., 2013; Frankenberg et al., 2013) for the period April 2009 to June 2011. We select only measurements which pass a series of quality criteria involving the absence of clouds and the retrieval precision for different species (Frankenberg et al., 2013; Risi et al., 2013).

To rigorously compare ECHAM5-wiso with GOSAT, the model output needs to be processed in two ways. First, we need to take into account the spatio-temporal sampling. GOSAT makes measurements only along its orbit, and not all measurements pass our quality selection. Therefore, we select only the locations and days for which GOSAT has made valid measurements. Such a selection makes sense because ECHAM5-wiso is nudged toward reanalysis, so that the atmospheric properties simulated by ECHAM5-wiso and observed by GOSAT can be compared at the daily scale.

Secondly, we need to take into account the instrument sensitivity. The column-integrated $\delta \mathrm{D}$ value retrieved by GOSAT is not exactly the column-integrated $\delta \mathrm{D}$ value which actually occurred. This is because retrievals are affected by 
atmospheric conditions such as the vertical profiles of temperature and water vapour or the presence of clouds. The "averaging kernels" describe how a given vertical profile in $\delta \mathrm{D}$, for given atmospheric conditions, translates into the GOSAT column-integrated $\delta$ D retrieval values (Rodgers and Connors, 2003). An averaging kernel is produced for each GOSAT measurement. Therefore, for each GOSAT measurement, we apply the corresponding averaging kernel to the model outputs. This allows us to compute the columnintegrated $\delta \mathrm{D}$ values that GOSAT would retrieve if it was flying in ECHAM5-wiso's simulated atmosphere (Risi et al., 2012a).

\section{Results and discussion}

\subsection{Present-day mean climate}

Gribanov et al. (2014) showed that the ECHAM5-wiso simulation results agree well with observations from Kourovka Observatory and the surrounding area for the year 2012. Since we analyse model results for the period 1960-2010, the period of model validation with meteorological observations has been extended. This section summarizes the results of the updated validation. Surface temperatures and precipitation rates in Yekaterinburg $\left(56.80^{\circ} \mathrm{N}, 60.60^{\circ} \mathrm{E}\right.$; WMO data for station Sverdlovsk retrieved from the KNMI Climate Explorer, http://climexp.knmi.nl/) were compared to the ECHAM5-wiso model values (calculated as the mean over the period 1960-2004, as more recent observations were not available). Simulated surface temperatures show a small cold bias of less than $1^{\circ} \mathrm{C}$ in the annual mean, with larger deviations (of up to $-3^{\circ} \mathrm{C}$ ) in winter. Precipitation rates simulated by ECHAM are slightly above observed values in the annual mean (by about $2 \mathrm{~mm} \mathrm{month}^{-1}$ ) and between October and June (by 2-8 $\mathrm{mm} \mathrm{month}^{-1}$ ), but up to $-16 \mathrm{~mm} \mathrm{month}^{-1}$ lower between July and September.

Figure 1 shows annual-mean patterns of simulated surface temperature $(T)$, total precipitation amount $(\mathrm{P})$, and oxygen18 content of precipitation $\left(\delta^{18} \mathrm{O}\right)$ for the region $0-160^{\circ} \mathrm{E}$, $40-80^{\circ} \mathrm{N}$, covering central and eastern Europe, Russia and parts of Asia.

Surface temperatures (Fig. 1a) decrease from southwest to northeast. Comparing model temperatures averaged over 1960-2010 with the CRU temperature reconstruction for the same period (University of East Anglia Climatic Research Unit (CRU), Jones and Harris, 2013), we find slightly colder values in the simulations than observed (in the range $-0.5-$ $-1.5^{\circ} \mathrm{C}$ ) in Eurasia and western Siberia. Conversely, simulated temperatures in central and eastern Siberia are higher by $\sim 0.5-1.5^{\circ} \mathrm{C}$ than the CRU data, with maximum differences of up to $5^{\circ} \mathrm{C}$ found for the Verkhoyansk Range.

Precipitation fields (Fig. 1b) are zonally aligned in the simulated annual mean pattern. Total precipitation decreases from 60 to $80 \mathrm{~mm} \mathrm{month}^{-1}$ at the East European Plain east- wards and arrives at minimum values of $20-30 \mathrm{~mm} \mathrm{month}^{-1}$ in a zone ranging from the southern part of the West Siberian Plain to northeast Siberia. Precipitation values peak in the Russian Far East in the Stanovoy Range. Compared to the CRU precipitation reconstruction (University of East Anglia Climatic Research Unit (CRU), Jones and Harris, 2013), simulated precipitation is higher by $10-20 \mathrm{~mm}^{-10 n \mathrm{th}^{-1}}$ north of $60^{\circ} \mathrm{N}$, and by up to about $30 \mathrm{~mm} \mathrm{month}^{-1}$ in the Russian Far East mountain areas. In the southern part of the West Siberian Plain, ECHAM produces slightly less precipitation than observed. The precipitation deficit increases with increasing continentality.

The simulated annual mean $\delta^{18} \mathrm{O}$ values of precipitation over Russia are plotted in Fig. 1c. Within Russia, $\delta^{18} \mathrm{O}$ values decrease from southwest to northeast. In contrast to temperature and precipitation, no global data set of observed $\delta^{18} \mathrm{O}$ in precipitation yet exists for comparison. The geographical distribution of GNIP stations shown in Fig. 1c illustrates the large observational gaps in Russia. A more rigorous modeldata comparison of $\delta^{18} \mathrm{O}$ will be presented further below.

Total column water vapour values of $\delta \mathrm{D}$, according to ECHAM5-wiso and to GOSAT satellite retrievals, are shown in Fig. 2. As there is no absolute calibration for columnintegrated $\delta$ D of GOSAT (Risi et al., 2013), we subtract the global average of $\delta \mathrm{D}$ for both GOSAT and ECHAM to enable an improved comparison focussing on the spatial distributions. The model captures the pattern of total column water vapour $\delta \mathrm{D}$ variations over Russia well (Fig. 2a and $\mathrm{b}$ ). Even some details such as the regional $\delta \mathrm{D}$ gradient southwest of Kourovka Observatory are resolved. Regarding the meridional $\delta \mathrm{D}$ gradient along the longitude zone including Kourovka, ECHAM5-wiso captures the northward depletion retrieved by GOSAT (Fig. 2c). Considering the zonal $\delta \mathrm{D}$ variation along the latitude zone including Kourovka (Fig. 2d), we find that ECHAM5-wiso tends to underestimate the eastward depletion associated with the continental effect. From $20^{\circ} \mathrm{E}$ to $120^{\circ} \mathrm{E}, \delta \mathrm{D}$ decreases by about $80 \%$ in GOSAT observations and by only about $40 \%$ in ECHAM5wiso.

For more quantitative analyses, we compare the climatology from our ECHAM5-wiso simulation results to available GNIP measurements. For each GNIP location, we restrict the data-model comparison to those months within the period 1960-2010, when measurements have been reported (see Table 1 for details). Thus, mean values of $T, \mathrm{P}$ and $\delta^{18} \mathrm{O}$ are calculated over different periods for each GNIP station and from ECHAM5-wiso. The results of this comparison are shown in Fig. 3. The uncertainty range indicated by the error bars is \pm 2 standard errors of the estimated mean values. In the following, uncertainty ranges always refer to the $95 \%$ confidence interval.

As expected from our nudging strategy, Fig. 3a shows good agreement between modelled surface temperatures and GNIP observations. Model results and observations are highly correlated $\left(r^{2} \sim 0.95\right)$ and lie close to a line with slope 

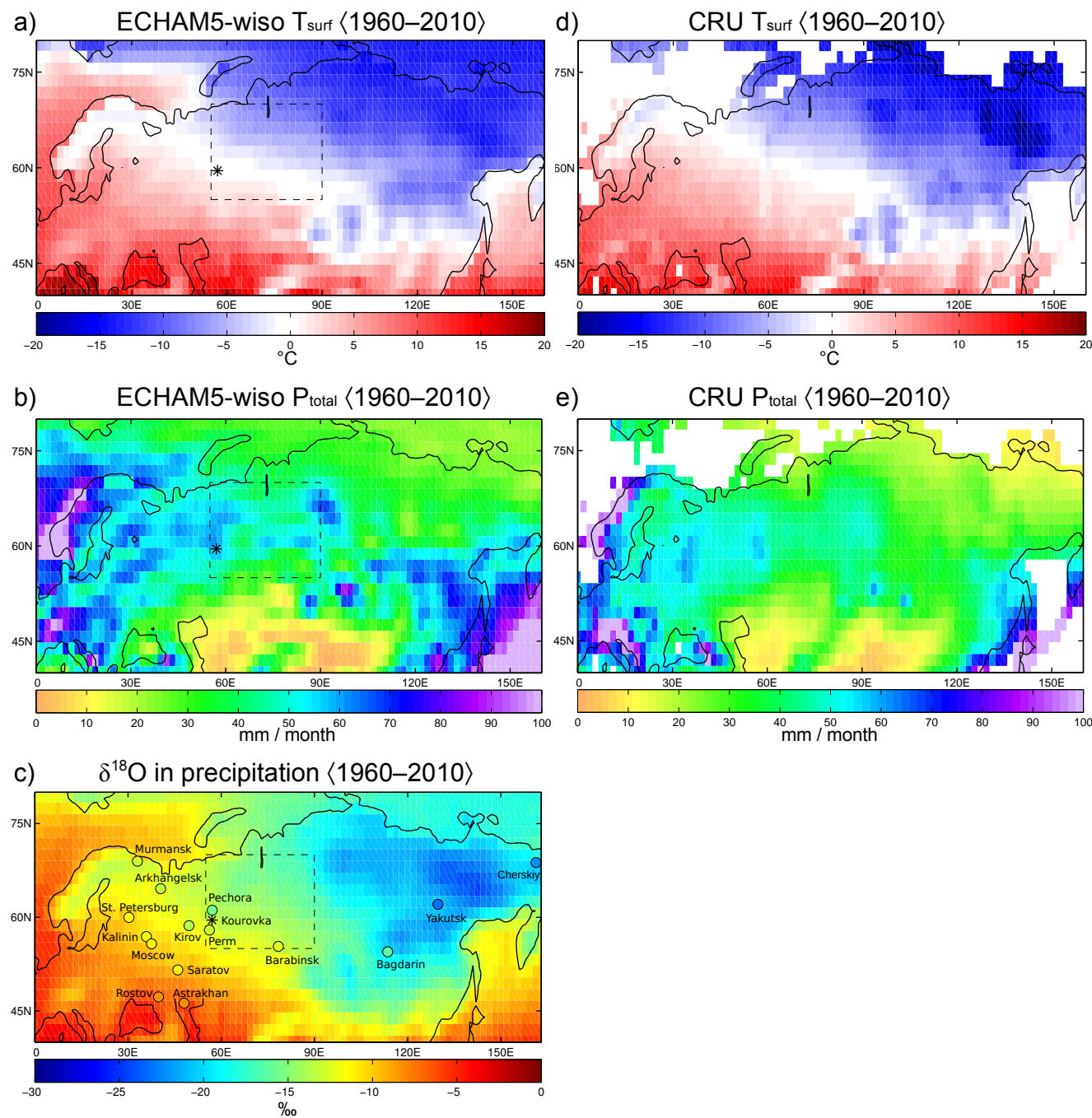

Figure 1. Left column: simulated mean annual values of (a) surface temperature, (b) precipitation, and (c) $\delta^{18} \mathrm{O}$ in precipitation, averaged over the period 1960-2010. Right column: CRU data of (d) surface temperature, and (e) precipitation amount, averaged over the same period. The circles in Fig. 1c mark the position of the various GNIP stations used for analyses in this study.

1. A linear fit, applying an algorithm which accounts for the uncertainties in both coordinates (Krystek and Anton, 2007), yields an optimum slope of $1.05 \pm 0.23$ and an optimum intercept of $(-0.75 \pm 1.45)^{\circ} \mathrm{C}$. The root mean square (RMS) difference between modelled and observed mean temperatures is $1.13^{\circ} \mathrm{C}$. A comparison of the averages over all stations (ECHAM5-wiso: $2.59^{\circ} \mathrm{C}$, GNIP: $3.30^{\circ} \mathrm{C}$ ) suggests that the model tends to underestimate the observed temperatures. Regarding individual stations, the largest difference is found for Perm, where the model is too cold by $2.9^{\circ} \mathrm{C}$. However, given the uncertainty ranges of observed and simulated temperatures, the conclusion of an overall cold bias of ECHAM5-wiso is not robust. The average variability of modelled and observed temperatures (i.e. the average length of the error bars) is virtually the same $\left( \pm 2.83{ }^{\circ} \mathrm{C}\right.$ vs. $\pm 2.88^{\circ} \mathrm{C}$ ). This indicates that ECHAM5-wiso captures the temporal variability of observed surface temperatures in Russia (note that the range of model values only reflects temporal variability while the observational range may also include measurement errors).

For precipitation the scatter of model results is larger (Fig. 3b), resulting in a correlation which is weaker than for temperature $\left(r^{2} \sim 0.73\right)$. The RMS difference between simulations and observations is about $10.5 \mathrm{~mm} \mathrm{month}^{-1}$, with the largest deviations for Murmansk $\left(+24 \mathrm{~mm} \mathrm{month}^{-1}\right)$ and for Rostov $\left(-19 \mathrm{mmmonth}^{-1}\right)$. The model results for these stations are clearly beyond the uncertainty range of a linear fit (slope $=1.25 \pm 0.16$ and intercept $\left.=(-6.68 \pm 5.78) \mathrm{mm} \mathrm{month}^{-1}\right)$. The average precipitation rate according to ECHAM5-wiso is $10 \%$ higher than observed $\left(48 \mathrm{~mm} \mathrm{month}^{-1}\right.$ vs. $\left.44 \mathrm{~mm} \mathrm{month}^{-1}\right)$, which points to a moist bias of the model. On the other hand, the model 

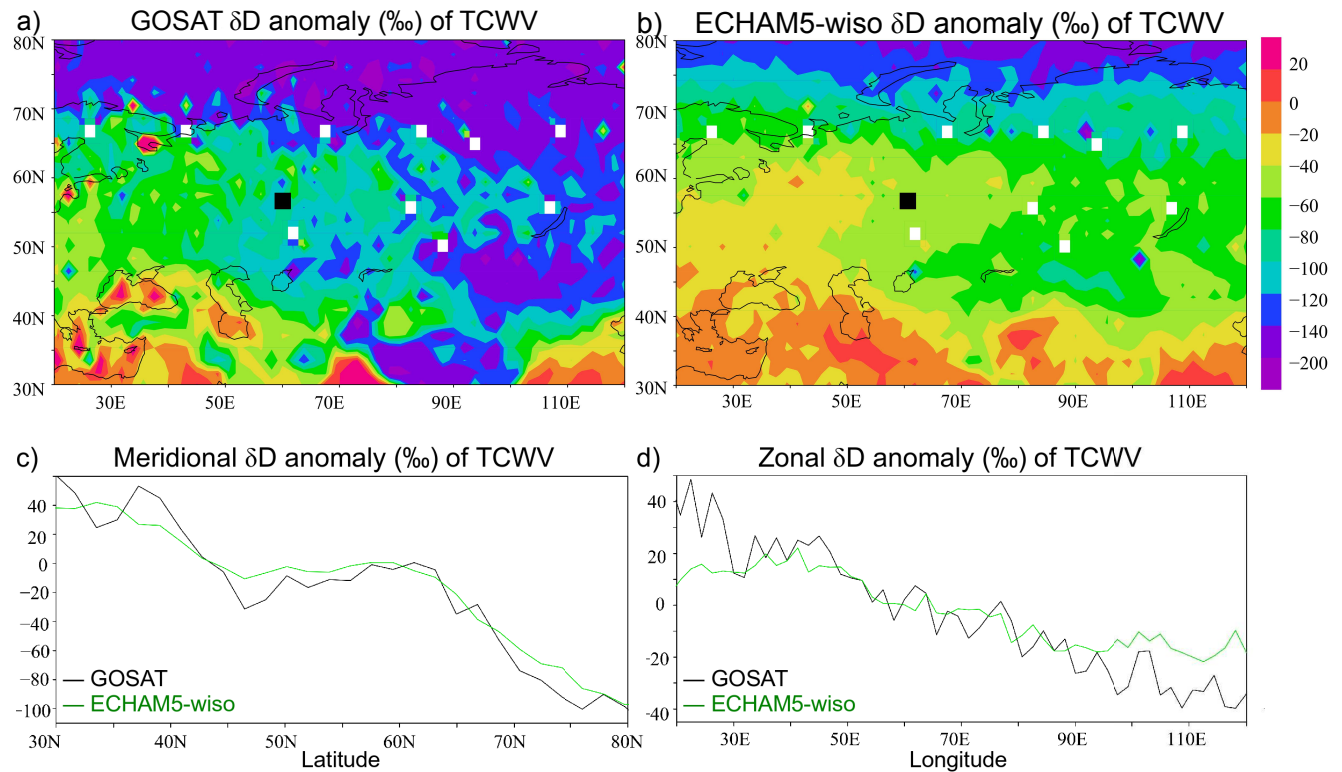

Figure 2. Distribution of annual-mean $\delta$ D in total column water vapour, (a) as observed by the GOSAT satellite, (b) as simulated by ECHAM, after collocation with GOSAT observations and convolution with the corresponding averaging kernels. In (a) and (b) the global average of $\delta \mathrm{D}$ has been subtracted to highlight spatial patterns, and the black squares indicate the location of Kourovka Observatory; white squares are grid cells with low-quality observations. (c) Meridional transects of observed (black) and simulated (green) $\delta \mathrm{D}$ averaged over the longitude band $50-70^{\circ} \mathrm{E}$ around Kourovka. The annual-mean $\delta \mathrm{D}$ value averaged over the area $30-80^{\circ} \mathrm{N}, 50-70^{\circ} \mathrm{E}$ has been subtracted to highlight the meridional variations. (d) Zonal transects of observed (black) and simulated (green) $\delta \mathrm{D}$ averaged over the latitude band $50-64^{\circ} \mathrm{N}$ around Kourovka. The annual-mean $\delta \mathrm{D}$ value averaged over the area $50-64^{\circ} \mathrm{N}, 20-120^{\circ} \mathrm{E}$ has been subtracted to highlight the zonal variations.

slightly underestimates the variability of observed precipitation rates $\left( \pm 6.55 \mathrm{~mm} \mathrm{month}^{-1}\right.$ vs. $\left.\pm 6.99 \mathrm{~mm} \mathrm{month}^{-1}\right)$.

Figure $3 \mathrm{c}$ indicates that ECHAM5-wiso captures annual mean $\delta^{18} \mathrm{O}$ records in Russia reasonably well. Model results and GNIP data are highly correlated $\left(r^{2} \sim 0.96\right)$ and coalesce along a line with a slope close to $1(0.97 \pm 0.11$; intercept: $(1.15 \pm 1.37) \% o)$. The RMS difference between model results and observations amounts to $1.05 \%$. ECHAM5wiso tends to overestimate observed $\delta^{18} \mathrm{O}$. The average over all stations is $-12.1 \%$ vs. $-13.6 \%$ according to GNIP. Maximum differences of up to $+4 \%$ are found for two stations in eastern Siberia (Cherskiy and Yakutsk) where ECHAM5-wiso does not simulate sufficient depletion. Uncertainty ranges of the simulated and observed means are rather the same $( \pm 1.17 \%$ o simulated vs. $\pm 1.16 \%$ observed). The model slightly underestimates the spatial gradients of $\delta^{18} \mathrm{O}$ observed in Russia. The meridional isotope gradient (observed slope: $-4.2 \%$ per $10^{\circ}$ latitude, simulated slope: $-3.6 \%$ per $10^{\circ}$ latitude), reflecting the meridional temperature gradient, is by about a factor of four to five larger than the zonal isotope variation (observed slope: $-0.9 \%$ oper $10^{\circ}$ longitude, simulated slope: $-0.8 \%$ oer $10^{\circ}$ longitude) associated with increasing continentality (not shown).

Studying anomalies of $\delta^{18} \mathrm{O}\left(\Delta \delta^{18} \mathrm{O}\right)$ and surface temperatures $(\Delta \mathrm{T})$, we find a linear relationship for all seasons with a typical slope of $0.5 \% 0^{\circ} \mathrm{C}^{-1}$ (Fig. 4). The correlation between GNIP $\Delta \mathrm{T}$ and $\Delta \delta^{18} \mathrm{O}$ is most pronounced in au- tumn (SON, $\left.r^{2}=0.69\right)$ and winter (DJF, $\left.r^{2}=0.61\right)$. In spring (MAM, $\left.r^{2}=0.50\right)$ and summer (JJA, $\left.r^{2}=0.40\right)$ the correlation is weaker, but still significant $(p \ll 0.05$ applying a $t$ test). The weaker coupling indicates that the $\delta^{18} \mathrm{O}$ signal during the warm season is significantly affected by other processes such as moisture recycling. ECHAM5-wiso simulates a similar seasonal relationship but the correlation between $\Delta \delta^{18} \mathrm{O}$ and $\Delta \mathrm{T}$ is higher than for the observations $\left(r^{2}=0.50\right.$ 0.79 ). The model overestimates the coupling between $\Delta \delta^{18} \mathrm{O}$ and $\Delta \mathrm{T}$ especially in spring $\left(r^{2}=0.79\right)$.

We now compare the simulated and observed seasonal cycle of precipitation $\delta^{18} \mathrm{O}$ in western Siberia (Fig. 5). The data exhibit seasonal variations ranging from $-25 \%$ in winter to $-5 \%$ in summer, closely following the seasonal cycle of temperature. Peak values of up to $-1 \%$ were observed in Perm during the second half of the 1980s. Despite the reported small annual-mean temperature biases, ECHAM5wiso correctly simulates the timing and magnitude of the seasonal variations of both temperature and $\delta^{18} \mathrm{O}$ (Fig. 5) in western Siberia. Observations and simulations from Pechora and Perm also show interannual variations, which will be discussed in the next section. 

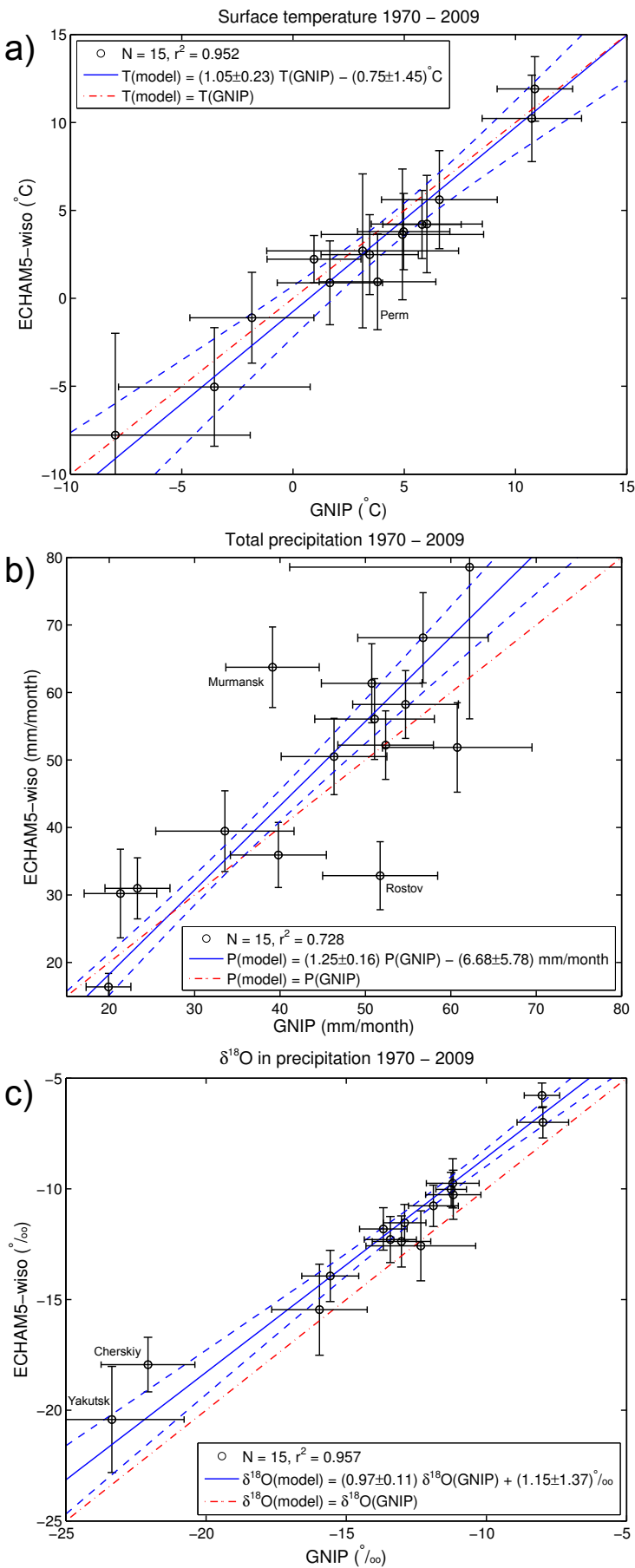

Figure 3. Comparison of mean values of (a) surface temperature, (b) precipitation amount, and (c) $\delta^{18} \mathrm{O}$ in precipitation for a selection of 15 GNIP stations located in Russia and the related ECHAM5-wiso model results (see text for details on station selection and mean value calculation at each station). Length of the error bars is \pm 2 standard errors of the estimated means. Straight lines are obtained from a weighted total least-squares algorithm accounting for uncertainties in both observations and model results (Krystek and Anton, 2007), dashed lines are $95 \%$ confidence intervals for the fits.

\subsection{Interannual to decadal variations over the last five decades}

The sampling period of precipitation $\delta^{18} \mathrm{O}$ in Russia is too short for a thorough investigation of the long-term variability seen in the West Siberian isotope and climate records shown in Fig. 5. To overcome this problem, we extend the time frame by considering model results for the period 1960 2010. Therefore, the following analysis of interannual to decadal variations of $T, \mathrm{P}$ and $\delta^{18} \mathrm{O}$ over Russia during the past decades is entirely based on model results. Unless stated otherwise, the model results are presented as anomalies from their long-term climatological mean (1961-1990). A zerophase bidirectional low-pass filter with a length of 24 equally weighted months is employed on the ECHAM5-wiso results to highlight long-term variability. To explore the potential influence of global warming during the period 1960-2010, we apply a $t$ test comparing the reference period with the period 1981-2010 (significance level is 5\%). In addition, we investigate linear long-term trends derived from a regression of annual-mean model results. The numerical results of this trend analysis are listed in Table 2.

At the global scale, (Fig. 6a, blue line), surface warming has been accompanied by increasing atmospheric moisture content (not shown) while modelled precipitation over land has slightly decreased (Fig. 6b). In parallel, global water vapour and precipitation have become progressively enriched with heavy water isotopes (Fig. 6c). The simulated increase of land surface temperatures is statistically significant. The trend analysis indicates a long-term increase of annualmean global land surface temperatures by $(1.23 \pm 0.01){ }^{\circ} \mathrm{C}$ per 50 years which is in the range of trend estimates based on observations (for a compilation of climatological observations see Hartmann et al., 2013, and references therein). Simulated anomalies of global land precipitation peaked in the mid-1970s which is also seen in global precipitation data sets. For more recent periods, the simulation does not reproduce the observed amplitude of interannual precipitation variability. However, the changes are statistically significant, and the modelled long-term decrease of global land precipitation by $(2.18 \pm 0.49) \mathrm{mm} \mathrm{month}^{-1}$ per 50 years is in line with observations (Hartmann et al., 2013; note that global precipitation trends there relate to the different period 19512008).

Long-term trends in $T$, $\mathrm{P}$, and $\delta^{18} \mathrm{O}$ are also found in western Siberia (averaged over the area $55-90^{\circ} \mathrm{E}, 55-70^{\circ} \mathrm{N}$ ) as well as at Kourovka (Fig. 6, red and green lines). Regional and local warming is statistically significant and occurred at lower rates than global ones in the annual mean $((1.19 \pm$ $0.18)^{\circ} \mathrm{C}$ per 50 years averaged over western Siberia and $(1.08 \pm 0.15)^{\circ} \mathrm{C}$ per 50 years in Kourovka). The long-term warming is particularly pronounced in winter (DJF), especially in western Siberia and Kourovka, where DJF warming rates are in the range $1.5-1.7^{\circ} \mathrm{C}$ per 50 years. Our model also suggests a positive long-term trend of annual precipitation. 

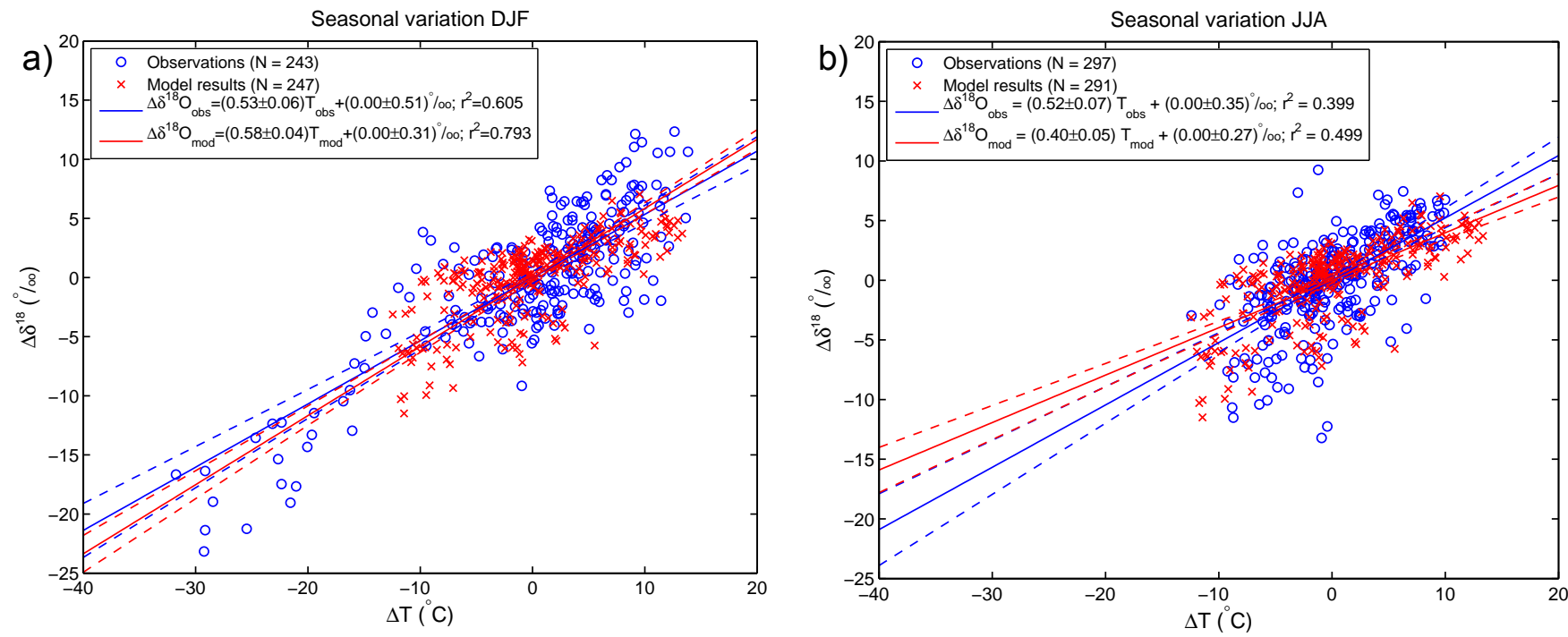

Figure 4. Relationship between $\delta^{18} \mathrm{O}$ and surface temperature. Shown are monthly anomalies $\left(\Delta \delta^{18} \mathrm{O}\right.$ and $\left.\Delta \mathrm{T}\right)$ according to monthly observations from 15 GNIP stations in Russia (circles) and the related ECHAM5-wiso model results (crosses), (a) winter season and (b) summer season. Solid lines are obtained from a least-squares linear fit of observations and model results; dashed lines indicate $95 \%$ confidence intervals for the fits.

Table 2. Linear trend estimates and $95 \%$ confidence intervals for annual and seasonal surface temperature, precipitation, and $\delta^{18} \mathrm{O}$ in precipitation simulated for the period 1960-2010.

\begin{tabular}{|c|c|c|c|c|}
\hline & Area & Annual mean & DJF & JJA \\
\hline \multirow{3}{*}{$\begin{array}{l}\text { Temperature } \\
\left({ }^{\circ} \mathrm{C} \text { per } 50 \text { years }\right)\end{array}$} & Global land & $1.23 \pm 0.01$ & $1.38 \pm 0.02$ & $1.12 \pm 0.01$ \\
\hline & W Siberia & $1.19 \pm 0.18$ & $1.72 \pm 1.37$ & $\{0.52 \pm 0.16\}$ \\
\hline & Kourovka & $1.08 \pm 0.15$ & $1.54 \pm 0.90$ & $\{0.91 \pm 0.27\}$ \\
\hline \multirow{3}{*}{$\begin{array}{l}\text { Precipitation } \\
\left(\mathrm{mm} \text { month }^{-1} \text { per } 50 \text { years }\right)\end{array}$} & Global land & $-2.18 \pm 0.49$ & $\{-0.46 \pm 1.56\}$ & $-2.82 \pm 0.76$ \\
\hline & W Siberia & $\{2.18 \pm 2.16\}$ & $3.10 \pm 3.75$ & $\{-0.38 \pm 12.0\}$ \\
\hline & Kourovka & $\{3.09 \pm 8.60\}$ & $\{3.28 \pm 11.0\}$ & $\{-11.9 \pm 63.0\}$ \\
\hline \multirow{3}{*}{$\begin{array}{l}\delta^{18} \mathrm{O} \\
(\% \text { per } 50 \text { years })\end{array}$} & Global land & $0.58 \pm 0.00$ & $0.36 \pm 0.01$ & $0.62 \pm 0.01$ \\
\hline & W Siberia & $0.48 \pm 0.05$ & $\{0.13 \pm 0.23\}$ & $0.55 \pm 0.03$ \\
\hline & Kourovka & $0.47 \pm 0.08$ & $\{-0.24 \pm 0.41\}$ & $\{0.58 \pm 0.11\}$ \\
\hline
\end{tabular}

Values for western Siberia are averaged over the area $55-90^{\circ}$ E, $55-70^{\circ}$ N. DJF represents December-February, JJA represents June-August. Curly brackets indicate that the underlying model anomalies for the period 1981-2010 are not significantly different from the reference period 1961-1990 (applying a $t$ test, significance level $=5 \%$ )

For both western Siberia and Kourovka, annual-mean precipitation rates have been increasing by $2-3 \mathrm{~mm}^{\text {month }}{ }^{-1}$ during the last 50 years, with a tendency towards enhanced DJF precipitation at the expense of JJA rainfall. However, except for winter precipitation in western Siberia, the changes are statistically insignificant, and the uncertainty range of the regional and local precipitation trends is high, exceeding the projected average long-term anomaly. Long-term trends of precipitation $\delta^{18} \mathrm{O}$ are also positive. The changes are small and at the detection limit ( $<1 \%$ op 50 years) but statistically significant everywhere at the annual timescale. For western Siberia we find that the long-term changes of $\delta^{18} \mathrm{O}$ are more pronounced during JJA than during DJF, which is opposite to the simulated seasonal temperature trends. The reason for this decoupling is that moisture import to western Siberia intensifies more in summer than in winter (not shown), while the opposite is simulated for precipitation. As a consequence, the isotopic signature of moisture available for precipitation is less affected by continental depletion during recent summer seasons than during recent winters.

At the regional and local scale the long-term trends are superimposed by strong interannual variability, reaching values 
a)
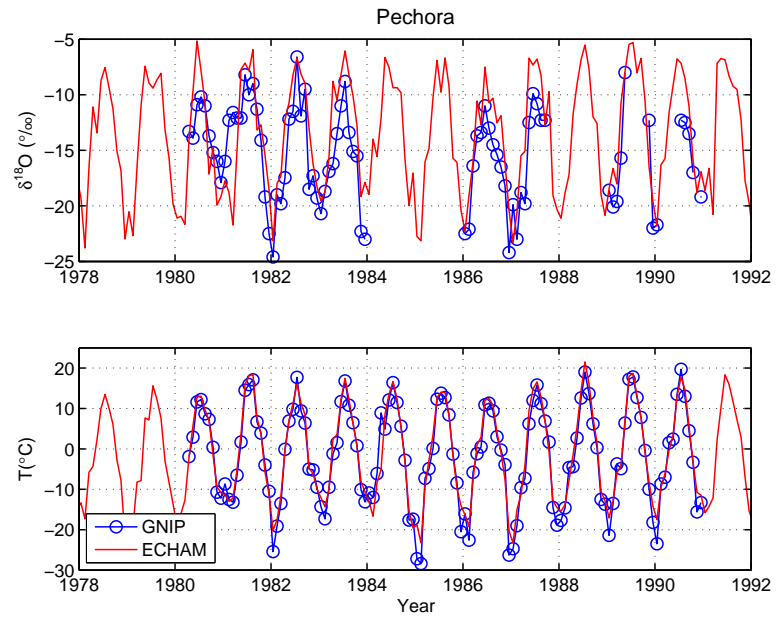

b)
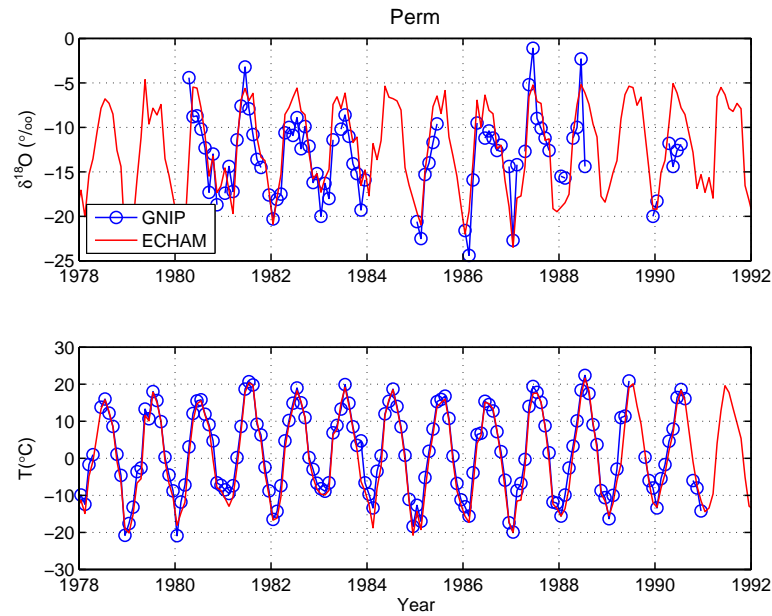

c)
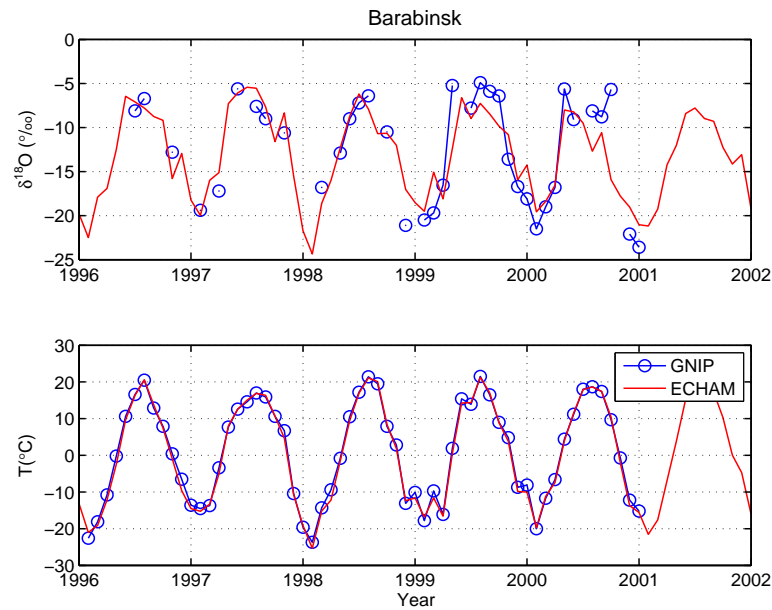

Figure 5. Observed versus modelled monthly $\delta^{18} \mathrm{O}$ values in precipitation for the period 1980-2000. Measurements of 3 GNIP stations located in western Siberia are plotted as blue circles: (a) Pechora, (b) Perm, (c) Barabinsk. The red line shows ECHAM5-wiso results corresponding to the same locations. Also shown are observed (blue) and modelled (red) surface temperatures.
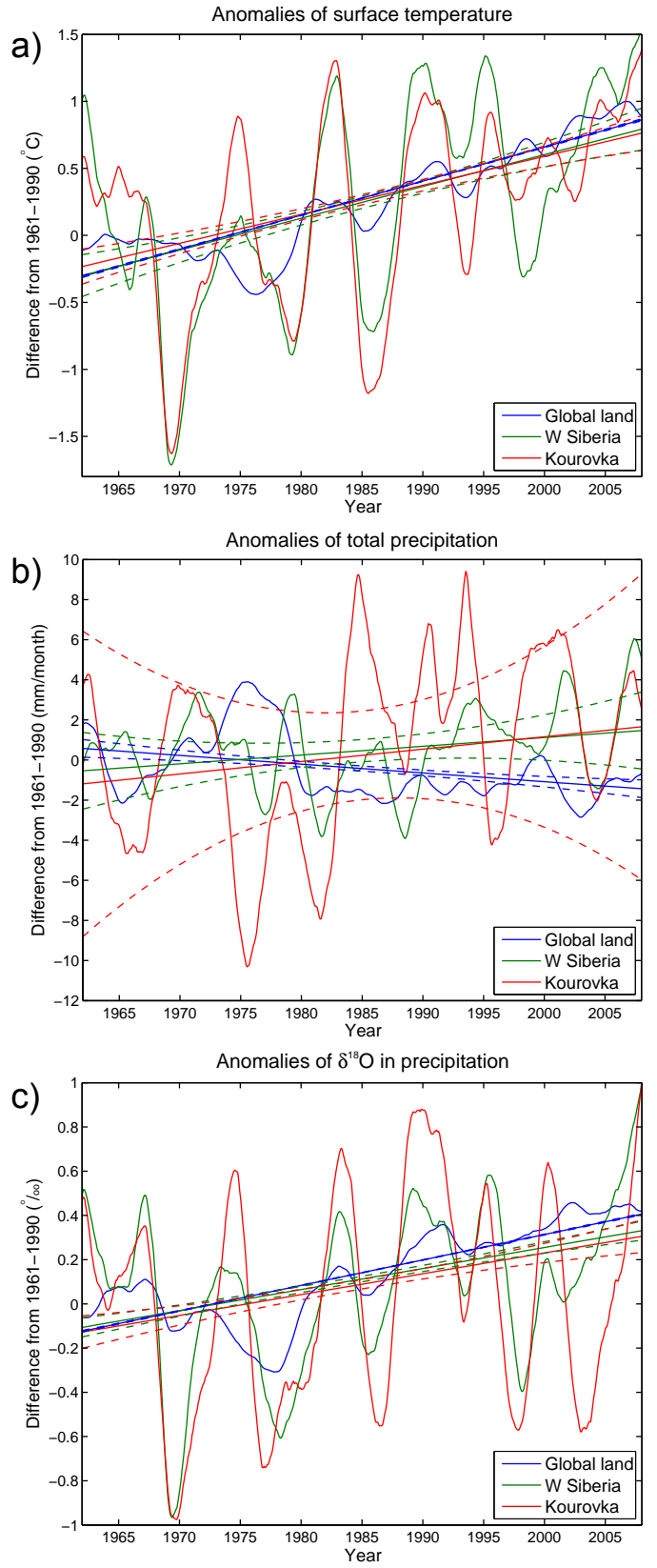

Figure 6. Simulated time series of (a) surface temperature, (b) precipitation, and (c) $\delta^{18} \mathrm{O}$ in precipitation for the period 1962-2008. Shown are anomalies from the climatological mean (reference period: 1961-1990). The ECHAM5-wiso results are averaged globally (blue line), for the region of western Siberia (green line), and interpolated to the location of Kourovka Observatory (red line). A zero-phase bidirectional low-pass filter with a length of 24 equally weighted months has been applied to the simulated monthly mean values for filtering short-term fluctuations. Straight lines are global (blue), regional (green) and local (red) trends obtained from leastsquare fits of annual-mean values for the period 1960-2010; dashed lines are $95 \%$ confidence intervals for the trends. See also Table 2 for a summary of numerical results. 
of up to $\pm 1.5^{\circ} \mathrm{C}, \pm 10 \mathrm{~mm} \mathrm{yr}^{-1}$, and $\pm 1 \%$, respectively. Temperature anomalies simulated for western Siberia and Kourovka have covaried since the late 1960s. During most of the simulation period, temperature differences between western Siberia and Kourovka are less than about $\pm 0.5^{\circ} \mathrm{C}$, with Kourovka showing larger fluctuations than western Siberia. Simulated precipitation anomalies for western Siberia and Kourovka appear to be less synchronous than is the case for temperature, particularly between 1995 and 2000 when the precipitation curves are out of phase. Moreover, in Kourovka the precipitation variability is considerably larger (by up to $10 \mathrm{~mm} \mathrm{month}^{-1}$ ) than its average for western Siberia. The larger deviation between the mean precipitation amount in West Siberia and the values in Kourovka as compared to the surface temperatures is not surprising, as precipitation is known to strongly vary at small spatial and temporal scales. Consistent with the temperature patterns, anomalies of $\delta^{18} \mathrm{O}$ in western Siberia and Kourovka are in phase most of the time and differ within $\pm 0.5 \%$, with the larger variability being simulated for Kourovka. In our simulation, $\delta^{18} \mathrm{O}$ and surface temperature mostly covary, which is not the case for the precipitation amount. However, $\delta^{18} \mathrm{O}$ and temperature are not rigidly coupled. This is indicated by our model results for the years around 1990, when temperatures in Kourovka were below the western Siberian average, while the opposite is obtained for $\delta^{18} \mathrm{O}$. The overall good agreement between mean temperature and $\delta^{18} \mathrm{O}$ changes in West Siberia and Kourovka is a key finding with respect to the objectives of the WSibIso Project. It indicates that Kourovka Observatory is a highly representative site for monitoring climate change in western Siberia.

While we find that annual and seasonal-mean values of $T, \mathrm{P}$ and $\delta^{18} \mathrm{O}$ have been slowly changing during the last decades (at least at the global scale), we do not arrive at a significant conclusion regarding potential changes in their interannual variance. Compared with the interannual variance between 1961 and 1990 (estimated from the standard deviation of detrended model results), the last decade (2001-2010) is characterized by increased variability of winter temperatures $\left(0.4{ }^{\circ} \mathrm{C}\right)$ and winter precipitation $\left(2 \mathrm{~mm}\right.$ month $\left.^{-1}\right)$ in western Siberia, and by increased variance of winter and summer precipitation rates $\left(3 \mathrm{~mm}\right.$ month $\left.^{-1}\right)$ in Kourovka. The last decade does not exhibit substantial changes in $\delta^{18} \mathrm{O}$ variability.

Further analyses of the temporal correlation between simulated values of $\delta^{18} \mathrm{O}$ in precipitation and surface temperatures (Fig. 7) reveal that the correlation of annual-mean values seen in Fig. 7a is mainly controlled by a strong linkage between surface temperature and $\delta^{18} \mathrm{O}$ in precipitation in western Siberia during winter (DJF). While the correlation coefficient between winter $T$ and $\delta^{18} \mathrm{O}$ can reach maximum values of up to 0.9 (Fig. 7b), the correlation between both climate variables is substantially weaker for summer (Fig. 7c). In the WSibIso target area, only one-quarter of the observed
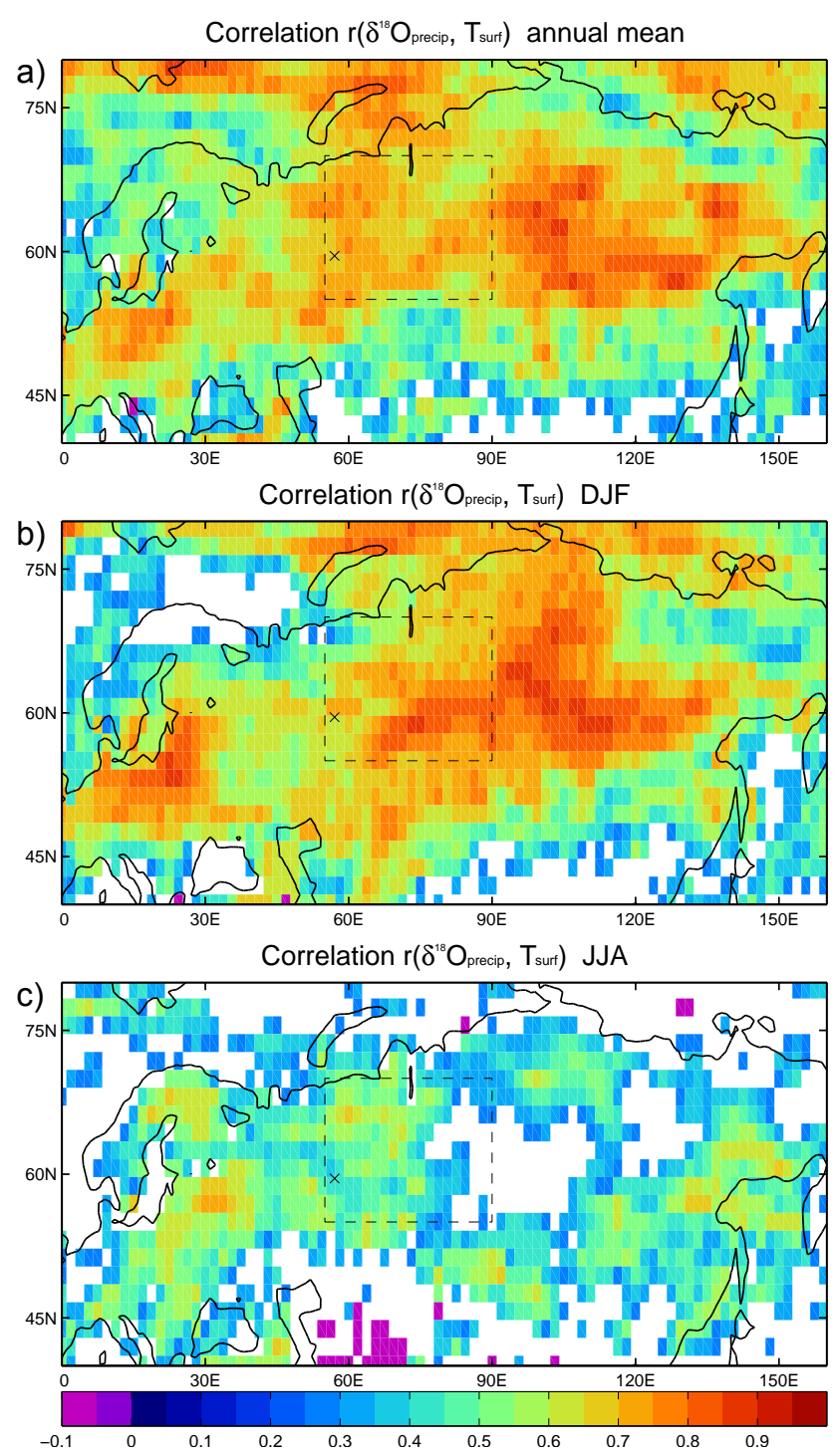

Figure 7. Temporal correlation between simulated values of $\delta^{18} \mathrm{O}$ in precipitation and surface temperatures for the period 1960-2010. Correlation coefficients are calculated for (a) annual mean, (b) winter (DJF), and (c) summer (JJA) values of temperature and $\delta^{18} \mathrm{O}$. Statistically insignificant areas (where $p \geq 0.05$ applying a $t$ test) are blanked.

interannual $\delta^{18} \mathrm{O}$ variability can be explained by a linear relationship with local surface air temperature changes.

We now explore the relationship between West Siberian climate and precipitation isotopic composition, and largescale atmospheric circulation. Previous studies have revealed a strong linkage between surface temperatures, $\delta^{18} \mathrm{O}$ in precipitation and the North Atlantic Oscillation (NAO) for major parts of Europe (e.g. Baldini et al., 2008; Field, 2010; Langebroek et al., 2011; Casado, et al., 2013). It is also known that the influence of the NAO on the large-scale atmospheric circulation is not bound to Europe but extends further east towards Russia (e.g. Halpert and Bell, 1997). Correlating 


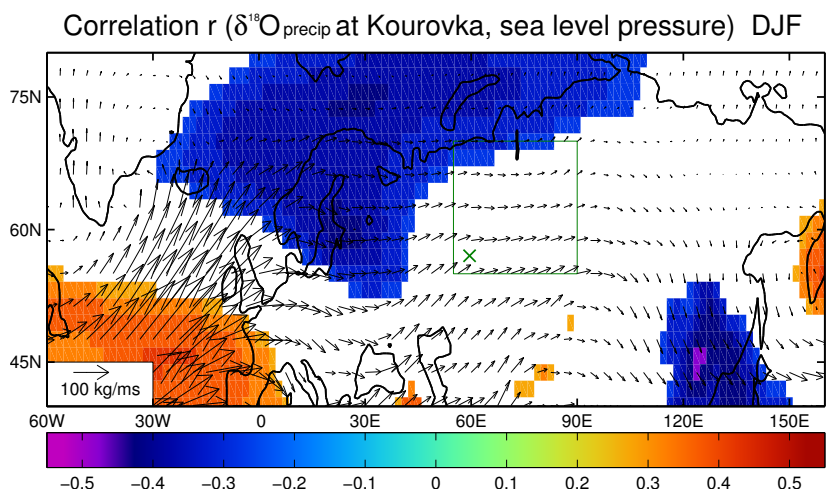

Figure 8. One-point correlation map showing the correlation between $\delta^{18} \mathrm{O}$ in precipitation at Kourovka and sea-level pressure during winter (DJF, correlation period is 1960-2010). Also shown is the average atmospheric moisture transport during DJF (vectors; only every second vector is drawn). The green box indicates western Siberia and the position of Kourovka is marked by a green cross.

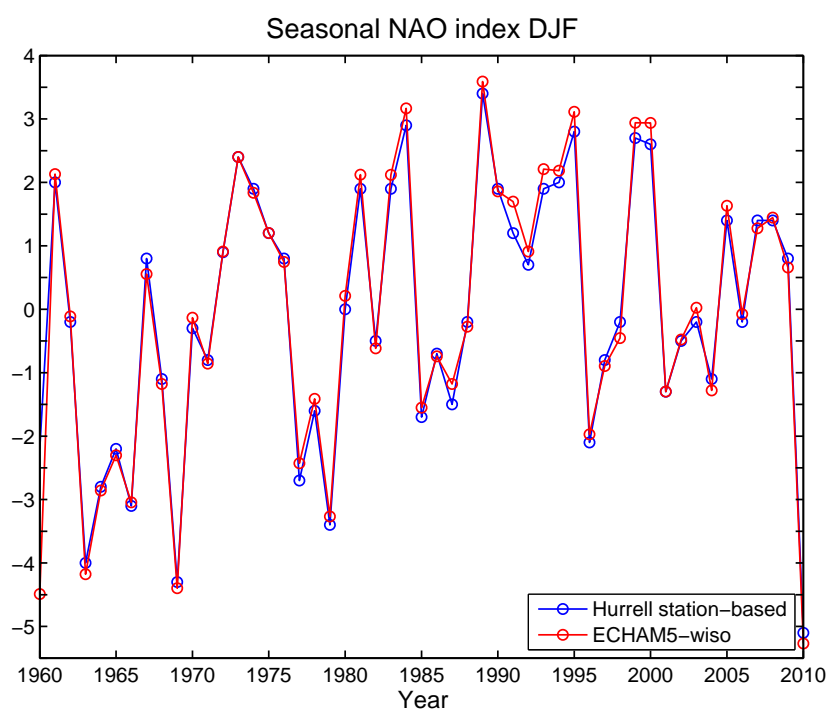

Figure 9. NAO winter (DJF) station index for the period 19602010, according to observations (blue line; Hurrell et al., 2013), and as simulated by the ECHAM5-wiso model (red line).

simulated $\delta^{18} \mathrm{O}$ values in Kourovka with the simulated global sea level pressure field, we find a pattern for winter which is characteristic for the NAO (Fig. 8; cf. Hurrell and Deser, 2009). Thus, as a next step we investigate the influence of $\mathrm{NAO}$ variations on temperature and $\delta^{18} \mathrm{O}$ variability over Russia.

Figure 9 shows the observed and simulated station-based NAO seasonal winter (DJF) index for the period 1960-2010. ECHAM5-wiso model faithfully captures the observed NAO index (reference stations are Ponta Delgada, Azores, and Stykkishólmur/Reykjavik, Iceland; Hurrell et al., 2013) consistent with the reanalysis pressure fields used for nudging. Minor deviations between the observed station-based index
Table 3. Correlation $r$ of $\delta^{18} \mathrm{O}$ in precipitation with meteorological variables at Kourovka according to model results for the period 1960-2010.

\begin{tabular}{lll}
\hline Variable & DJF & JJA \\
\hline Surface temperature $T_{\text {surf }}$ & 0.62 & 0.43 \\
Total precipitation $\mathrm{P}$ & $\{0.10\}$ & -0.45 \\
Large-scale precipitation & $\{0.10\}$ & $\{-0.25\}$ \\
Convective precipitation $\mathrm{P}_{\mathrm{C}}$ & $\{0.03\}$ & -0.44 \\
Evaporation E & $\{-0.20\}$ & -0.31 \\
Soil wetness & $\{0.09\}$ & -0.45 \\
$T_{\text {surf }}$ (seasons $\left.\mid \mathrm{P}<\langle\mathrm{P}\rangle\right)$ & 0.68 & 0.46 \\
& $(29$ seasons) & $(30$ seasons) \\
$T_{\text {surf }}$ (seasons $\left.\mid \mathrm{P}_{\mathrm{C}}<\left\langle\mathrm{P}_{\mathrm{C}}\right\rangle\right)$ & 0.62 & 0.63 \\
& $(50$ seasons*) & $(23$ seasons) \\
$T_{\text {surf }}$ (seasons $\left.\mid \mathrm{E}<\langle\mathrm{E}\rangle\right)$ & 0.62 & 0.55 \\
& $(25$ seasons) & $(27$ seasons) \\
\hline
\end{tabular}

DJF represents December-February, JJA represents June-August. Values in curly brackets are statistically insignificant ( $p \geq 0.05$ applying a $t$ test). The lower three rows show the correlation with surface temperature if only seasons are considered in which total precipitation $\mathrm{P}$, convective precipitation $\mathrm{P}_{\mathrm{C}}$ or evaporation $\mathrm{E}$ are below their respective arithmetic long-term values $\langle\mathrm{P}\rangle,\left\langle\mathrm{P}_{\mathrm{C}}\right\rangle$, and $\langle\mathrm{E}\rangle$.

* Convective winter precipitation at Kourovka was zero except for one season (in which $\mathrm{P}_{\mathrm{C}}<0.1 \mathrm{~mm}$ month $^{-1}$ ).

and the modelled values can be attributed to the chosen model resolution T63, which can result in a slightly different average surface pressure of a relatively large grid cell as compared to a point-like station location. A correlation analysis of this simulated station-based NAO seasonal winter (DJF) index with modelled values of $T, \mathrm{P}$, and $\delta^{18} \mathrm{O}$ reveals that the NAO influence on surface temperature, precipitation amount and $\delta^{18} \mathrm{O}$ in precipitation extends in a broad band from $\mathrm{Eu}-$ rope to northern Siberia (Fig. 10). To a large extent, the covariation between winter NAO and $\delta^{18} \mathrm{O}$ (Fig. 10a) is controlled by air temperature. Winters are mild in years when the NAO is strong, which is indicated by the positive correlation between NAO index and DJF surface temperatures shown in Fig. 10b. Winter precipitation in northern Russia also increases when the NAO is strong (Fig. 10c).

Our analyses shown in Fig. 10 reveal that in wintertime the NAO-associated atmospheric circulation changes have a slightly weaker impact on precipitation $\delta^{18} \mathrm{O}(r \sim 0.6)$ over western Siberia than on the surface temperatures in this region $(r \sim 0.7)$. On the contrary, $\delta^{18} \mathrm{O}$ in precipitation is much more strongly correlated to the NAO than the precipitation amount itself $(r \sim 0.3)$. This exposes the potential of reconstructing past changes of the NAO strength from various $\delta^{18} \mathrm{O}$ records, for example those retrieved from lake sediments, speleothems, or tree rings (e.g. Sidorova et al., 2010) from this region. The ECHAM5-wiso results indicate that archives storing the $\delta^{18} \mathrm{O}$ signal of winter precipitation should be suitable for such a NAO reconstruction.

While the interannual variability of $\delta^{18} \mathrm{O}$ in winter precipitation can be largely attributed to temperature variations in western Siberia associated with the NAO, we do not find 


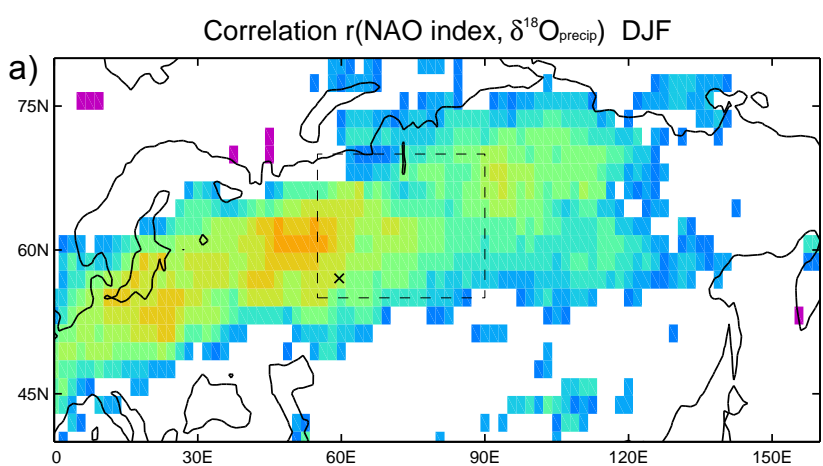

Correlation r(NAO index, surface temperature) DJF
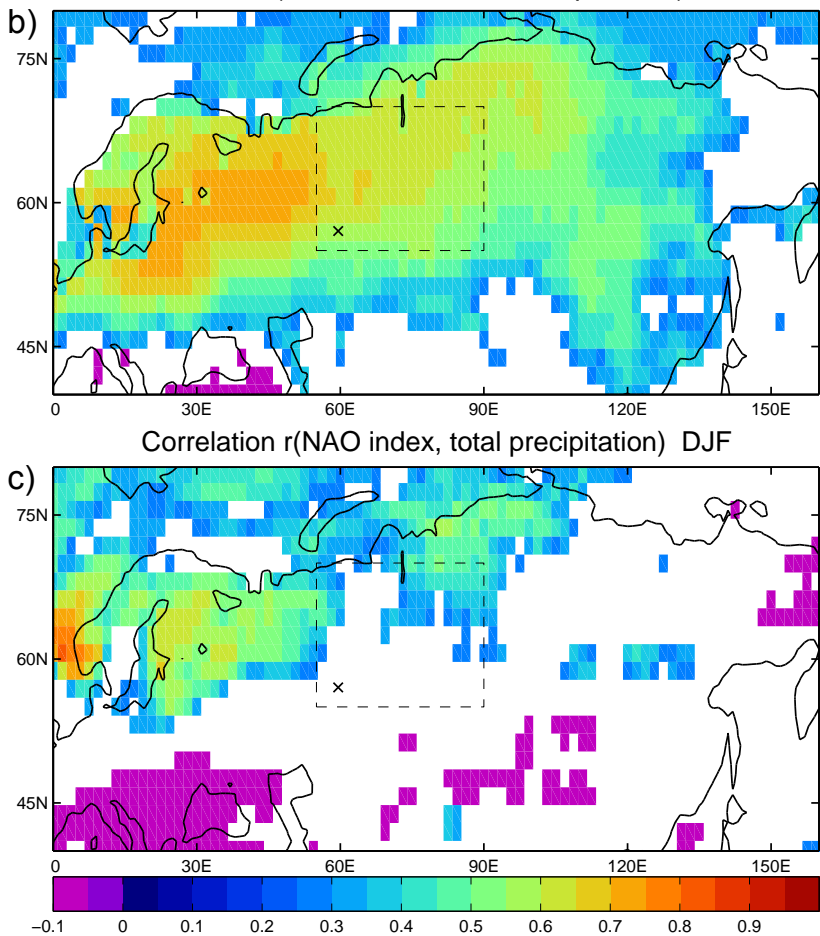

Figure 10. Temporal correlation between station-based NAO winter (DJF) index and (a) $\delta^{18} \mathrm{O}$ in precipitation, (b) surface temperature, and (c) total precipitation amount. Statistically insignificant areas (where $p \geq 0.05$ applying a $t$ test) are blanked.

such a teleconnection for the summer. Previous studies have shown that evapotranspiration fluxes significantly contribute to summer precipitation in Russia, and estimated that the regional moisture recycling rates can exceed $80 \%$ (e.g. Koster et al., 1993; Numaguti, 1999; Risi et al., 2013). Accordingly, Kurita et al. (2003, 2004) have suggested that snowmelt and subsequent evaporation of soil moisture carrying the isotopic imprint of winter precipitation could significantly influence the isotopic composition of regional precipitation, counterbalancing the positive coupling between temperature and $\delta^{18} \mathrm{O}$. Studying one-point correlation maps for JJA, we find that $\delta^{18} \mathrm{O}$ at Kourovka is negatively correlated with the regional soil moisture reservoir (Fig. 11a) and local evaporation (see Table 3) which is in line with moisture recycling
Correlation $r\left(\delta^{18} \mathrm{O}_{\text {precip }}\right.$ at Kourovka, soil moisture) JJA

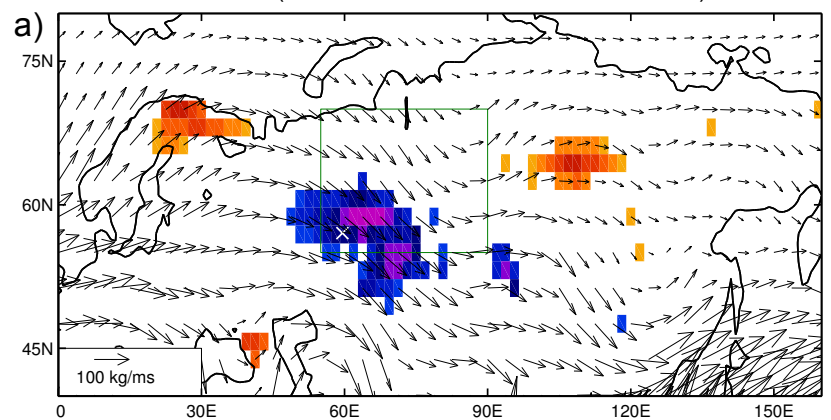

Correlation $r$ ( $\delta^{18} O_{\text {precip }}$ at Kourovka, total precipitation) JJA

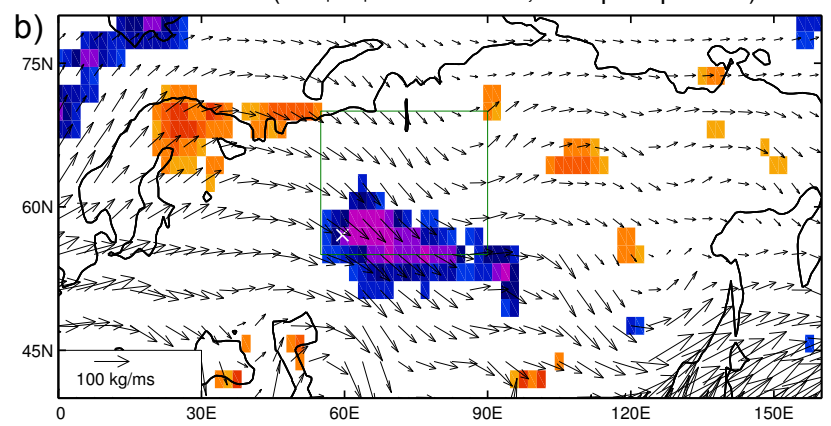

Correlation $r\left(\delta^{18} O_{\text {precip }}\right.$ at Kourovka, convective precipitation) JJA

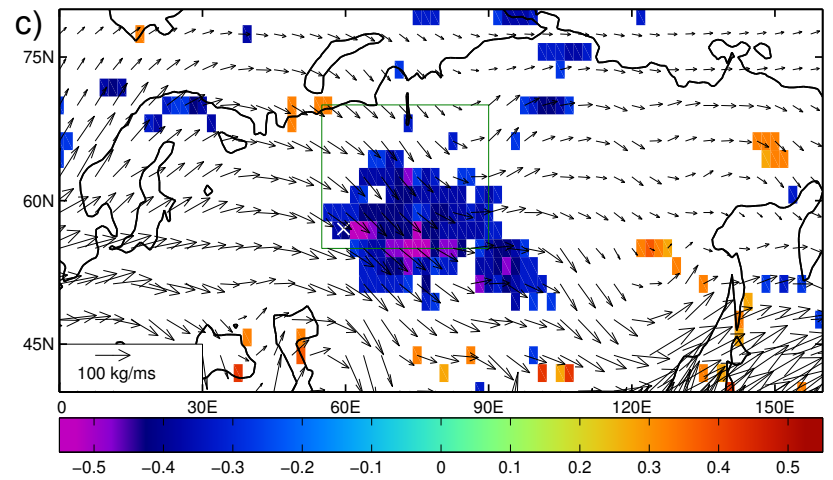

Figure 11. One-point correlation map showing the correlation between $\delta^{18} \mathrm{O}$ in precipitation at Kourovka during summer (JJA) with (a) soil moisture, (b) total precipitation, and (c) convective precipitation. Also shown is the average atmospheric moisture transport during JJA (vectors; only every second vector is drawn). The green box indicates western Siberia and the position of Kourovka is marked by a white cross. The correlation period is 1960-2010. Statistically insignificant areas (where $p \geq 0.05$ applying a $t$ test) are blanked. See also Table 3 for numbers.

through re-evaporation. Moreover, we identify a negative correlation between $\delta^{18} \mathrm{O}$ and total precipitation (Fig. 11b), which is mainly due to the variability of convective precipitation (Fig. 11c, see also Table 3). If we consider only years in which convective precipitation is below the arithmetic longterm average, the correlation between $\delta^{18} \mathrm{O}$ and local surface temperature rises from $r \sim 0.4$ to $r \sim 0.6$ (i.e. comparable to winter values, cf. Table 3 ). In the opposite case (convective precipitation above the long-term average) the correlation 
between $\delta^{18} \mathrm{O}$ and surface temperature decreases to $r \sim 0.3$. This suggests that the isotope signal in West Siberian summer precipitation is rather controlled by the temperature variability at the level of condensation than by temperatures on the ground. In principle, a correlation of $\delta^{18} \mathrm{O}$ with vertical temperatures should permit us to identify the altitude range of precipitation formation. However, correlating monthly-mean values we did not arrive at conclusive results.

Figure 11 clearly reveals that the summer $\delta^{18} \mathrm{O}$ signal at Kourovka reflects hydrometeorological changes at the regional scale. Regarding precipitation and the seasonal-mean moisture flow, the correlation pattern is asymmetric. Areas in which the correlations are statistically significant are rather small upwind of Kourovka, but more extended downwind. Downwind areas may contribute to the isotopic signal at Kourovka through mixing - i.e. in situations of transient perturbations of the mean atmospheric flow. In fact, according to Fukutomi et al. (2004), Kourovka lies in the Siberian summer storm-track zone with high synoptic-scale eddy activity. This is reflected in our model results by greater monthly variability of atmospheric moisture transport towards Kourovka during summer than during winter. In summer, monthly moisture fluxes vary within $\sim \pm 35 \%$ in magnitude and within $\sim \pm 25^{\circ}$ in flow direction, while in winter monthly-mean fluxes vary within $\sim \pm 10 \%$ in magnitude and $\sim \pm 15^{\circ}$ in flow direction, respectively. These findings, as well as the results of our correlation analyses, are probably overly smoothed to fully resolve effects of moisture recycling, atmospheric convection, and transient perturbations, as the effective timescales of these processes can be considerably shorter than a month.

The link between $\delta^{18} \mathrm{O}$ and climate during the West Siberian summer deserves further investigations. The effects of atmospheric convection and transient perturbations could be investigated by analysing the evolution of $\delta^{18} \mathrm{O}$ at the timescale of single meteorological events, which may also involve the use of second order isotopic data (d-excess or ${ }^{17} \mathrm{O}$ excess; e.g. Landais et al., 2010; Guan et al., 2013). Moisture recycling and the origin of advected moisture could be investigated by moisture tagging, that is by simulating the dispersal of numerical water tracers evaporating from different predefined source regions (e.g. Koster et al., 1986; Numaguti, 1999; Risi et al., 2013). Nonetheless, our findings for the summer are in line with previous studies arguing that variations of $\delta^{18} \mathrm{O}$ in precipitation are rather a regionally integrated signal of several climate variables than a proxy for either local temperature or precipitation changes (e.g. on a global scale: Schmidt et al., 2005; for Western Europe: Langebroek et al., 2011).

\section{Summary and conclusions}

Using the few available observations as well as a new simulation from the isotope-enabled atmospheric general circulation model ECHAM5-wiso covering the period 19582013, we have investigated the spatiotemporal variations in the isotopic composition of precipitation in Russia during recent decades. In its nudged configuration, the model simulates temperature and precipitation fields over western Siberia within reasonable error margins, providing a realistic framework for investigating the model performance for $\delta^{18} \mathrm{O}$. The model reproduces the spatial pattern of precipitation $\delta^{18} \mathrm{O}$ when compared with averaged observations from 15 stations of the Global Network of Isotopes in Precipitation between 1970 and 2009. The model has difficulties capturing the amount of $\delta^{18} \mathrm{O}$ depletion in eastern Siberia, while temperature and precipitation are correctly simulated.

According to our model results, temperature is the predominant factor, controlling up to $80 \%$ of the variability of annual-mean and winter precipitation $\delta^{18} \mathrm{O}$ in Russia on interannual to decadal timescales. Interannual variations in winter temperature and isotope signals show a strong imprint of the North Atlantic Oscillation. During summer, local temperature has only a minor impact (about 20\%) on the variability of the isotopic composition of West Siberian precipitation. Instead, our analyses indicate that $\delta^{18} \mathrm{O}$ integrates effects of regional hydrometeorological processes on timescales shorter than a month which have not been explicitly considered in this study. The results are in line with moisture recycling through evaporation, involving the delayed reevaporation of isotopically depleted winter precipitation retained in snowmelt and soil water. The isotopic summer signal is significantly influenced by convective precipitation formation, which does not occur in this region in winter. We also find enhanced variability of moisture transports towards western Siberia. The relative importance of these processes should be further investigated with higher temporal resolution, or by using second order isotopic data (e.g. deuterium excess) as well as numerical moisture tagging diagnostics. Our results indicate that $\delta^{18} \mathrm{O}$ has the potential to reveal hydrometeorological regime shifts in future summers, which are otherwise difficult to identify.

Recent observations reveal significant isotopic variability on the diurnal and daily timescale (Gribanov et al., 2014). The impact of short-term variations on the isotopic signal seen in the monthly GNIP records cannot be analysed, but continuous monitoring of water vapour $\delta^{18} \mathrm{O}$ and daily sampling of precipitation $\delta^{18} \mathrm{O}$ will permit the study of processes on the event scale. Regarding Kourovka Observatory, where such a monitoring programme has recently been established, we find that the simulated variability of temperature and $\delta^{18} \mathrm{O}$ at this location is similar to model results averaged over the entire West Siberian region. Therefore, we conclude that this location is highly suitable to monitor isotopic changes all over western Siberia. 
Acknowledgements. This research was supported by a grant from the Russian government under the contract 11.G34.31.0064. The help of S. Rast, Max Planck Institute for Meteorology, Hamburg, for providing model support regarding ECHAM5 nudging aspects is thankfully acknowledged. S. Terzer, IAEA Isotope Hydrology Section, Vienna, provided valuable information regarding water isotope data from Russia. We thank C. Purcell, Alfred Wegener Institute, Bremerhaven, for language checking and two anonymous referees for constructive reviews.

Edited by: H. Wernli

\section{References}

Araguas-Araguas, L., Froelich, K., and Rozanski, K.: Deuterium and oxygen-18 isotope composition of precipitation and atmospheric moisture, Hydrol. Process., 14, 13411355, doi:10.1002/1099-1085(20000615)14:8<1341::AIDHYP983>3.0.CO;2-Z, 2000.

Baldini, L. M., McDermott, F., Foley, A. M., and Baldini, J. U. L.: Spatial variability in the European winter precipitation $\delta^{18} \mathrm{O}-$ NAO relationship: implications for reconstructing NAO-mode climate variability in the Holocene, Geophys. Res. Lett., 35, L04709. doi:10.1029/2007GL032027, 2008.

Bengtsson, L., Hodges, K. I., Koumoutsaris, S., Zahn, M., and Keenlyside, N.: The changing atmospheric water cycle in Polar Regions in a warmer climate, Tellus A, 63, 907-920, doi:10.1111/j.1600-0870.2011.00534.x, 2011.

Berkelhammer, M., Hu, J., Bailey, A., Noone, D. C., Still, C. J., Barnard, H., Gochis, D., Hsiao, G. S., Rahn, T., and Turnipseed, A.: The nocturnal water cycle in an open-canopy forest, J. Geophys. Res. Atmos., 118, 10225-10242, doi:10.1002/jgrd.50701, 2013.

Berrisford, P., Dee, D., Poli, P., Brugge, R., Fielding, K., Fuentes, M., Kallberg, P., Kobayashi, S., Uppala, S., and Simmons, A.: The ERA-Interim archive Version 2.0, ERA Report Series No. 1, European Centre for Medium-Range Weather Forecasts, Reading, UK, 2011.

Boesch, H., Deutscher, N. M., Warneke, T., Byckling, K., Cogan, A. J., Griffith, D. W. T., Notholt, J., Parker, R. J., and Wang, Z.: $\mathrm{HDO} / \mathrm{H}_{2} \mathrm{O}$ ratio retrievals from GOSAT, Atmos. Meas. Tech., 6 , 599-612, doi:10.5194/amt-6-599-2013, 2013.

Craig, H.: Isotopic Variations in Meteoric Waters, Science, 133, 1702-1703, doi:10.1126/science.133.3465.1702, 1961.

Dansgaard, W.: The abundance of $\mathrm{O}^{18}$ in atmospheric water and water vapour, Tellus, 5, 461-469, doi:10.1111/j.21533490.1953.tb01076.x, 1953.

Dansgaard, W.: Stable isotopes in precipitation, Tellus, 16, 436468, doi:10.1111/j.2153-3490.1964.tb00181.x, 1964.

Dee, D. P., Uppala, S. M., Simmons, A. J., Berrisford, P., Poli, P., Kobayashi, S., Andrae, U., Balmaseda, M. A., Balsamo, G., Bauer, P., Bechtold, P., Beljaars, A. C. M., van de Berg, L., Bidlot, J., Bormann, N., Delsol, C., Dragani, R., Fuentes, M., Geer, A. J., Haimberger, L., Healy, S. B., Hersbach, H., Hólm, E. V., Isaksen, L., Kållberg, P., Köhler, M., Matricardi, M., McNally, A. P., Monge-Sanz, B. M., Morcrette, J.-J., Park, B.-K., Peubey, C., de Rosnay, P., Tavolato, C., Thépaut, J.-N., and Vitart, F.: The ERA-Interim reanalysis: configuration and performance of the data assimilation system, Q. J. Roy. Meteor. Soc., 137, 553-597, doi:10.1002/qj.828, 2011.

Field, R. D.: Observed and modeled controls on precipitation delta O-18 over Europe: From local temperature to the Northern Annular Mode, J. Geophys. Res., 115, D12101, doi:10.1029/2009JD013370, 2010.

Frankenberg C., Wunch, D., Toon, G., Risi, C., Scheepmaker, R., Lee, J.-E., Wennberg, P., and Worden, J.: Water vapor isotopologue retrievals from high-resolution GOSAT shortwave infrared spectra, Atmos. Meas. Tech., 6, 263-274, doi:10.5194/amt-6263-2013, 2013.

Fukutomi, Y., Masuda, K., and Yasunari, T.: Role of storm track activity in the interannual seesaw of summer precipitation over northern Eurasia, J. Geophys. Res., 109, D02109, doi:10.1029/2003JD003912, 2004.

Gribanov, K., Jouzel, J., Bastrikov, V., Bonne, J.-L., Breon, F.-M., Butzin, M., Cattani, O., Masson-Delmotte, V., Rokotyan, N., Werner, M., and Zakharov, V.: Developing a Western Siberia reference site for tropospheric water vapour isotopologue observations obtained by different techniques (in situ and remote sensing), Atmos. Chem. Phys. Discuss., in press, 2014.

Gryazin, V., Risi, C., Jouzel, J., Kurita, N., Worden, J., Frankenberg, C. and Bastrikov, V., Gribanov, K., and Stukova, O: The added value of water isotopic measurements for understanding model biases in simulating the water cycle over Western Siberia, Atmos. Chem. Phys. Discuss., 14, 4457-4503, doi:10.5194/acpd14-4457-2014, 2014.

Guan, H., Zhang, X., Skrzypek, G., Sun, Z., and Xu, X.: Deuterium excess variations of rainfall events in a coastal area of South Australia and its relationship with synoptic weather systems and atmospheric moisture sources, J. Geophys. Res. Atmos., 118, 1123-1138, doi:10.1002/jgrd.50137, 2013.

Haese, B., Werner, M., and Lohmann, G.: Stable water isotopes in the coupled atmosphere-land surface model ECHAM5JSBACH, Geosci. Model Dev., 6, 1463-1480, doi:10.5194/gmd6-1463-2013, 2013.

Hagemann, S.: An improved land surface parameter dataset for global and regional climate models. Report 336, Max Planck Institute for Meteorology, Hamburg, Germany, 2002.

Hagemann, S., Arpe, K., and Roeckner, E.: Evaluation of the hydrological cycle in the ECHAM5 model, J. Clim., 19, 3810-3827, doi:10.1175/JCLI3831.1, 2006.

Halpert, M. S. and Bell, G. D.: Climate Assessment for 1996, Bull. Am. Meteorol. Soc., 78, 1038, doi:10.1175/15200477(1997)078<1038:CAF>2.0.CO;2, 1997.

Hartmann, D. L., Klein Tank, A. M. G., Rusticucci, M., Alexander, L. V., Brönnimann, S., Charabi, Y., Dentener, F. J., Dlugokencky, E. J., Easterling, D. R., Kaplan, A., Soden, B. J., Thorne, P. W., Wild, M., and Zhai, P. M.: Observations: Atmosphere and Surface. In: Climate Change 2013: The Physical Science Basis. Contribution of Working Group I to the Fifth Assessment Report of the Intergovernmental Panel on Climate Change, edited by: Stocker, T. F., Qin, D., Plattner, G.-K., Tignor, M., Allen, S. K., Boschung, J., Nauels, A., Xia, Y., Bex, V., and Midgley, P. M., Cambridge University Press, Cambridge, United Kingdom and New York, NY, USA, 159-254, 2014.

Hoffmann, G., Werner, M., and Heimann, M.: Water isotope module of the ECHAM atmospheric general circulation model: A study 
on timescales from days to several years, J. Geophys. Res., 103, 16871-16896, doi:10.1029/98JD00423, 1998.

Hurrell, J. W. and Deser, C.: North Atlantic climate variability: The role of the North Atlantic Oscillation, J. Mar. Syst., 78, 28-41, doi:10.1016/j.jmarsys.2008.11.026, 2009.

Hurrell, J. and National Center for Atmospheric Research Staff (Eds.): The Climate Data Guide: Hurrell North Atlantic Oscillation (NAO) Index (station-based), retrieved from https://climatedataguide.ucar.edu/climate-data/ hurrell-north-atlantic-oscillation-nao-index-station-based (last access: 16 September 2013), 2013.

IAEA/WMO: Global Network of Isotopes in Precipitation: The GNIP Database, iaea.org [online], available from: http:// www-naweb.iaea.org/napc/ih/IHS_resources_gnip.html (last access: 3 July 2013), 2013.

IPCC: Emission Scenarios: A Special Report of Working Group III of the Intergovernmental Panel on Climate Change, Nakicenovic, edited by: N. and Swart, R., Cambridge University Press, Cambridge, UK, 570 pp., 2000.

IPCC: Climate Change 2013: The Physical Science Basis. Contribution of Working Group I to the Fifth Assessment Report of the Intergovernmental Panel on Climate Change, edited by: Stocker, T. F., Qin, D., Plattner, G.-K., Tignor, M., Allen, S. K., Boschung, J., Nauels, A., Xia, Y., Bex, V., and Midgley, P. M., Cambridge University Press, Cambridge, United Kingdom and New York, NY, USA, 1535 pp., 2013.

Joussaume, S., Sadourny, R., and Jouzel, J.: A general circulation model of water isotope cycles in the atmosphere, Nature, 311, 24-29, doi:10.1038/311024a0, 1984.

Jouzel, J. and Merlivat, L.: Deuterium and oxygen 18 in precipitation: Modeling of the isotopic effects during snow formation, J. Geophys. Res., 89, 11749-11757, doi:10.1029/JD089iD07p11749, 1984.

Jouzel, J., Russell, G. L., Suozzo, R. J., Koster, R. D., White, J. W. C., and Broecker, W. S.: Simulations of the HDO and $\mathrm{H}_{2}^{18} \mathrm{O}$ atmospheric cycles using the NASA GISS general circulation model: The seasonal cycle for present-day conditions, J. Geophys. Res., 92, 14739-14760, doi:10.1029/JD092iD12p14739, 1987.

Jouzel, J., Hoffmann, G., Koster, R. D., and Masson, V.: Water isotopes in precipitation: data/model comparison for present-day and past climates, Q. Sci. Rev., 19, 363-379, doi:10.1016/S02773791(99)00069-4, 2000.

Koster, R., Jouzel, J., Souzzo, R., Russell, G., Broecker, W., Rind, D., and Eagleson, P.: Global sources of local precipitation as determined by the NASA/GISS GCM, Geophys. Res. Lett., 13, 121-124, doi:10.1029/GL013i002p00121, 1986.

Koster, R. D., de Valpine, D. P., and Jouzel, J.: Continental water recycling and $\mathrm{H}_{2}^{18} \mathrm{O}$ concentrations, Geophys. Res. Lett., 20, 22152218, doi:10.1029/93GL01781, 1993.

Krishnamurti, T. N., Xue, J., Bedi, H. S., Ingles, K., and Oosterhof, D.: Physical initialization for numerical weather prediction over the tropics, Tellus B, 43, 53-81, doi:10.1034/j.16000889.1991.t01-2-00007.x, 1991.

Krystek, M. and Anton, M.: A weighted total least-squares algorithm for fitting a straight line, Meas. Sci. Technol., 18, 34383442, doi:10.1088/0957-0233/18/11/025, 2007.

Kurita, N., Numaguti, A., Sugimoto, A., Ichiyanagi, K., and Yoshida, N.: Relationship between the variation of isotopic ra- tios and the source of summer precipitation in eastern Siberia, J. Geophys. Res., 108, 4339, doi:10.1029/2001JD001359, 2003.

Kurita, N., Yoshida, N., and Chayanova, E. A.: Modern isotope climatology of Russia: A first assessment, J. Geophys. Res., 109, D3102, doi:10.1029/2003JD003404, 2004.

Landais, A., Risi, C., Bony, S., Vimeux, F., Descroix, L., Falourd, S., and Bouygues, A.: Combined measurements of ${ }^{17} \mathrm{O}_{\text {excess }}$ and d-excess in African monsoon precipitation: Implications for evaluating convective parameterizations, Earth Planet. Sci. Lett., 298, 104-112, doi:10.1016/j.eps1.2010.07.033, 2010.

Langebroek, P. M., Werner, M., and Lohmann, G.: Climate information imprinted in oxygen-isotopic composition of precipitation in Europe, Earth Planet. Sci. Lett., 311, 144-154, doi:10.1016/j.eps1.2011.08.049, 2011.

Lee, J. E. and Fung, I.: "Amount effect" of water isotopes and quantitative analysis of post-condensation processes, Hydrol. Process., 22, 1-8, doi:10.1002/Hyp.6637, 2008.

Lin, S. J. and Rood, R. B.: Multidimensional fluxform semi Lagrangian transport schemes, Mon. Weather Rev., 124, 2046-2070, doi:10.1175/15200493(1996)124<2046:MFFSLT>2.0.CO;2, 1996.

Masson-Delmotte, V., Schulz, M., Abe-Ouchi, A., Beer, J., Ganopolski, A., González Rouco, J. F., Jansen, E., Lambeck, K., Luterbacher, J., Naish, T., Osborn, T., Otto-Bliesner, B., Quinn, T., Ramesh, R., Rojas, M., Shao, X., and Timmermann, A.: Information from Paleoclimate Archives. In: Climate Change 2013: The Physical Science Basis. Contribution of Working Group I to the Fifth Assessment Report of the Intergovernmental Panel on Climate Change, edited by: Stocker, T. F., Qin, D., Plattner, G.K., Tignor, M., Allen, S. K., Boschung, J., Nauels, A., Xia, Y., Bex, V., and Midgley, P. M., Cambridge University Press, Cambridge, United Kingdom and New York, NY, USA, 383-464, 2013.

Mathieu, R., Pollard, D., Cole, J. E., White, J. W. C., Webb, R. S., and Thompson, S. L.: Simulation of stable water isotope variations by the GENESIS GCM for modern conditions, J. Geophys. Res., 107, 4037, doi:10.1029/2001JD900255, 2002.

Merlivat, L. and Jouzel, J.: Global Climatic Interpretation of the deuterium-oxygen 18 relationship for precipitation, J. Geophys. Res., 84, 5029-5033, doi:10.1029/JC084iC08p05029, 1979.

Merlivat, L., Ravoire, J., Vergnaud, J. P., and Lorius, C.: Tritium and deuterium content of snow in Groenland, Earth Planet. Sci. Lett., 19, 235-240, doi:10.1016/0012-821X(73)90121-0, 1973.

Noone, D. and Simmonds, I.: Associations between $\delta^{18} \mathrm{O}$ of water and climate parameters in a simulation of atmospheric circulation for 1979-95, J. Clim., 15, 3150-3169, doi:10.1175/15200442(2002)015<3150:ABOOWA>2.0.CO;2, 2002.

Numaguti, A.: Origin and recycling processes of precipitating water over the Eurasian continent: Experiments using an atmospheric general circulation model, J. Geophys. Res., 104, 1957-1972, doi:10.1029/1998JD200026, 1999.

Rast, S., Brokopf, R., Cheedela, S.-K., Esch, M., Gayler, Kirchner, I., Kornblüh, L., Rhodin, A., Schmidt, H., Schulzweida, U., and Wieners, K.-H., 2013: User manual for ECHAM6, Reports on Earth System Science 13, Max Planck Institute for Meteorology, Hamburg, Germany, 2013.

Risi, C., Bony, S., Vimeux, F., and Jouzel, J.: Water-stable isotopes in the LMDZ4 general circulation model: Model evaluation for present-day and past climates and applications to climatic in- 
terpretations of tropical isotopic records, J. Geophys. Res., 115, D12118, doi:10.1029/2009JD013255, 2010a.

Risi, C., Bony, S., Vimeux, F., Frankenberg, C., Noone, D., and Worden, J.: Understanding the Sahelian water budget through the isotopic composition of water vapor and precipitation, J. Geophys. Res., 115, D24110, doi:10.1029/2010JD014690, 2010b.

Risi, C., Noone, D., Worden, J., Frankenberg, C., Stiller, G., Kiefer, M., Funke, B., Walker, K., Bernath, P., Schneider, M., Wunch, D., Sherlock, V., Deutscher, N., Griffith, D., Wennberg, P. O., Strong, K., Smale, D., Mahieu, E., Barthlott, S., Hase, F., García, O., Notholt, J., Warneke, T., Toon, G., Sayres, D., Bony, S., Lee, J., Brown, D., Uemura, R., and Sturm, C.: Processevaluation of tropospheric humidity simulated by general circulation models using water vapor isotopologues. Part 1: Comparison between models and observations, J. Geophys. Res., 117, D05303, doi:10.1029/2011JD016621, 2012.

Risi, C., Noone, D., Frankenberg, C., and Worden, J.: Role of continental recycling in intraseasonal variations of continental moisture as deduced from model simulations and water vapor isotopic measurements, Water Ressources Res., 49, 1-21, doi:10.1002/wrcr.20312, 2013.

Roeckner, E., Bäuml, G., Bonaventura, L., Brokopf, R., Esch, M., Giorgetta, M., Hagemann, S., Kirchner, I., Kornblueh, L., Manzini, E., Rhodin, A., Schlese, U., Schulzweida, U., and Tompkins, A.: The atmospheric general circulation model ECHAM5, Part 1, Model description. Report No. 349, Max Planck Institute for Meteorology, Hamburg, Germany, 2003.

Roeckner, E., Brokopf, R., Esch, M., Giorgetta, M., Hagemann, S., Kornblueh, L., Manzini, E., Schlese, U., and Schulzweida, U.: Sensitivity of simulated climate to horizontal and vertical resolution in the ECHAM5 atmosphere model, J. Clim., 19, 37713791, doi:10.1175/JCLI3824.1, 2006.

Rodgers, C. D. and Connor, B. J: Intercomparison of remote sounding instruments, J. Geophys. Res., 108, 4116, doi:10.1029/2002JD002299, 2003.

Rokotyan, N. V, Zakharov, V. I., Gribanov, K. G, Bréon, F-M., Jouzel, J., Imasu, R., Werner, M., Butzin, M, Petri, C., Warneke, $\mathrm{T}$., and Notholt, J.: Retrieval of $\delta^{18} \mathrm{O}$ and $\delta \mathrm{D}$ in the atmospheric water vapour from high-resolution ground-based FTIR measurements of solar radiation in near-infrared, Atm. Meas. Tech. Discuss., 7, 195-231, doi:10.5194/amtd-7-195-2014, 2014.

Saurer, M., Schweingruber, F., Vaganov, E. A., Shiyatov, S. G., and Siegwolf, R.: Spatial and temporal oxygen isotope trends at the northern tree-line in Eurasia, Geophys. Res. Lett., 29, 1296, doi:10.1029/2001GL013739, 2002.

Schmidt, G. A., Hoffmann, G., Shindell, D. T., and Hu, Y.: Modeling atmospheric stable water isotopes and the potential for constraining cloud processes and stratospheretroposphere water exchange, J. Geophys. Res., 110, D21314, doi:10.1029/2005JD005790, 2005.

Sidorova, O. V., Siegwolf, R. T. W., Saurer, M., Naurzbaev, M. M., Shashkin, A. V., and Vaganov, E. A.: Spatial patterns of climatic changes in the Eurasian north reflected in Siberian larch tree-ring parameters and stable isotopes, Global Change Biol., 16, 10031018, doi:10.1111/j.1365-2486.2009.02008.x, 2010.
Sonntag, C., Neureuther, P., Kalinke, C., Münnich, K. O., Klitzsch, E., and Weistroffer, K.: Zur Paläoklimatik der Sahara, Naturwissenschaften, 63, 479-479, doi:10.1007/BF00624580, 1976.

Sturm, C., Zhang, Q., and Noone, D.: An introduction to stable water isotopes in climate models: benefits of forward proxy modelling for paleoclimatology, Clim. Past, 6, 115-129, doi:10.5194/cp-6-115-2010, 2010.

Tindall, J. C., Valdes, P. J., and Sime, L. C.: Stable water isotopes in HadCM3: Isotopic signature of El Niño-Southern Oscillation and the tropical amount effect, J. Geophys. Res., 114, D04111, doi:10.1029/2008JD010825, 2009.

Tingley, M. P. and Huybers, P.: Recent temperature extremes at high northern latitudes unprecedented in the past 600 years, Nature, 496, 201-208, doi:10.1038/nature11969, 2013.

University of East Anglia Climatic Research Unit (CRU), edited by: Jones, P. and Harris, I., CRU Time Series (TS) high resolution gridded data version 3.21, available from: http://badc.nerc.ac.uk/view/badc.nerc.ac.uk_ATOM_ _ACTIVITY_0c08abfc-f2d5-11e2-a948-00163e251233 (last access: 18 September 2013), NCAS British Atmospheric Data Centre, .

Uppala, S. M., Kållberg, P. W., Simmons, A. J., Andrae, U., da Costa Bechtold, V., Fiorino, M., Gibson, J. K., Haseler, J., Hernandez, A., Kelly, G. A., Li, X., Onogi, K., Saarinen, S., Sokka, N., Allan, R. P., Andersson, E., Arpe, K., Balmaseda, M. A., Beljaars, A.C.M., van de Berg, L., Bidlot, J., Bormann, N., Caires, S., Chevallier, F, Dethof, A., Dragosavac, M., Fisher, M., Fuentes, M., Hagemann, S., Hólm, E., Hoskins, B. J., Isaksen, L., Janssen, P. A. E. M., Jenne, R., McNally, A. P., Mahfouf, J.-F., Morcrette, J.-J., Rayner, N. A., Saunders, R. W., Simon, P., Sterl, A., Trenberth, K. E., Untch, A., Vasiljevic, D., Viterbo, P., and Woollen, J.: The ERA-40 re-analysis, Q. J. Roy. Meteor. Soc., 131, 2961-3012, doi:10.1256/qj.04.176, 2005.

Vuille, M. and Werner, M.: Stable isotopes in precipitation recording South American summer monsoon and ENSO variability: observations and model results, Clim. Dyn., 25, 401-413, doi:10.1007/s00382-005-0049-9, 2005.

Werner, M. and Heimann, M.: Modeling interannual variability of water isotopes in Greenland and Antarctica, J. Geophys. Res., 107, 4001, doi:10.1029/2001JD900253, 2002.

Werner, M., Heimann, M., and Hoffmann, G.: Isotopic composition and origin of polar precipitation in present and glacial climate simulations, Tellus B, 53, 53-71, doi:10.1034/j.16000889.2001.01154.x, 2001.

Werner, M., Langebroek, P. M., Carlsen, T., Herold, M., and Lohmann, G.: Stable water isotopes in the ECHAM5 general circulation model: Toward high-resolution isotope modeling on a global scale, J. Geophys. Res., 116, D15109, doi:10.1029/2011jd015681, 2011.

Yoshimura, K., Frankenberg, C., Lee, J., Kanamitsu, M., Worden, J., and Röckmann, T.: Comparison of an isotopic atmospheric general circulation model with new quasi-global satellite measurements of water vapor isotopologues, J. Geophys. Res., 116, D19118, doi:10.1029/2011JD016035, 2011. 